\title{
Article \\ Effect of Operating Conditions on the Performance of Gas-Liquid Mixture Roots Pumps
}

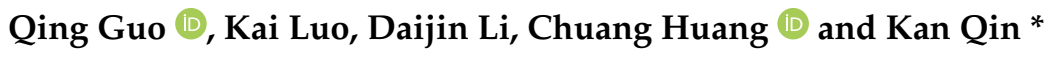 \\ School of Marine Science and Technology, Northwestern Polytechnical University, Xi'an 710072, China; \\ gqing1992@mail.nwpu.edu.cn (Q.G.); nwpu_wyh@nwpu.edu.cn (K.L.); lidaijin@nwpu.edu.cn (D.L.); \\ huangchuang@nwpu.edu.cn (C.H.) \\ * Correspondence: kan.qin@nwpu.edu.cn
}

check for updates

Citation: Guo, Q.; Luo, K.; Li, D.; Huang, C.; Qin, K. Effect of Operating Conditions on the Performance of Gas-Liquid Mixture Roots Pumps. Energies 2021, 14, 5361. https:// doi.org/10.3390/en14175361

Academic Editor: Adrián Mota Babiloni

Received: 30 July 2021

Accepted: 26 August 2021

Published: 28 August 2021

Publisher's Note: MDPI stays neutral with regard to jurisdictional claims in published maps and institutional affiliations.

Copyright: (c) 2021 by the authors. Licensee MDPI, Basel, Switzerland. This article is an open access article distributed under the terms and conditions of the Creative Commons Attribution (CC BY) license (https:// creativecommons.org/licenses/by/ $4.0 /)$.
Abstract: The performance of the gas-liquid mixture Roots pump at different operating conditions is investigated in this paper. The pump efficiency was first increased from $48 \%$ to $64 \%$, and then decreased to $59 \%$ with the increased inlet $\mathrm{CO}_{2}$ volume fraction (from 0.8 to 1 ). The increased rotational speed (from $1000 \mathrm{rpm}$ to $4000 \mathrm{rpm}$ ) and pressure ratio (from 2 to 10) can lead to a reduction in the pump's efficiency from $67 \%$ to $43 \%$ and from $48 \%$ to $33 \%$, respectively. The variation in the pump's efficiency is affected by the volumetric efficiency and the flow efficiency simultaneously. The high pressure and the $\mathrm{CO}_{2}$ volume fraction in the outlet zone can increase the leakage, leading to a reduction in the volumetric efficiency. The flow efficiency decreases with the increase in the local pressure at the outlet zone and the backflow density. The outlet zone pressure can also affect the fluid properties by changing the density of the gas phase. Therefore, the combined effect of the outlet zone pressure and the working fluid properties is considered to be the main factor affecting the performance. This paper further explores the suitability of Roots pumps for compressing gas-liquid mixtures.

Keywords: Roots pump; multiphase flow; computational fluid dynamics; energy systems

\section{Highlights}

- The performance of the gas-liquid mixture Roots pump at different inlet $\mathrm{CO}_{2}$ volume conditions, rotational speeds, and pressure ratios is investigated;

- The influence of the pressure ratio and the gas volume fraction on the pump leakage is discussed;

- The outlet zone pressure and the working fluid properties are considered to be the main factors affecting the performance of the gas-liquid mixture Roots pump.

\section{Introduction}

Increasing the operating depth and speed is always the aim with unmanned underwater vehicles (UUVs), and is primarily determined by the power system. The use of electrodynamic systems is limited because of the low performance of batteries. The performance of the open-cycle thermal power system is sensitive to the operating depth [1]. When the operating depth increases, the engine backpressure increases, and the system efficiency is severely degraded. One of the alternatives to alleviate the influence of the operating depth is the semi-closed-cycle thermal power system. The gas-liquid mixture is formed by mixing the exhaust gas with the seawater, and then pumped out of the vehicles. Hence, the engine backpressure remains stable, ensuring that the system efficiency is acceptable in the operational condition of great depth.

For this promising power cycle, the key question is how to pump out the gas-liquid mixture effectively. Moreover, the gas-liquid mixture pump should operate efficiently under different pressure ratios and gas volume fractions. Various types of pumps involve gas-liquid mixture flow during their operation. Si et al. [2] evaluated the performance of 
two centrifugal pumps under gas-liquid two-phase conditions, and obtained the mechanism of performance variations via flow field analysis. Cao et al. [3] conducted an experiment to study the pressure distribution in a multiphase twin-screw compressor, and proposed a mathematical model to predict the pressure in the working chamber. He et al. [4] experimentally studied the influence of oil injection on the performance of twinscrew compressors. The results show that the oil contributes to improving the volumetric efficiency and reduces the exhaust temperature. Lobsinger et al. [5] established a twodimensional simulation model of a fixed-type balanced vane pump, and adopted the model to analyze the cavitation characteristics and the performance variations under different inlet gas volume fractions of the pump. Zhang et al. [6] numerically studied the internal flow characteristics of a multiphase rotodynamic pump and analyzed the flow behavior of the gas phase in the pump flow channels. In [7], several types of gas-liquid mixture pump were discussed, and the Roots pump was selected.

In the existing studies on the profile of Roots pumps, Cai et al. [8] designed the Roots pump profile using the Assur-group-associated virtual linkage method. Bhuyan and Ghosh [9] established a mathematical model to parameterize the Roots pump profile in terms of the base circle and the waist circle radii; they also conducted simulations to obtain the flow characteristics of different types of Roots pumps. The relationship between Roots pump performances and rotor profiles was established by using multiple regression analysis and the neurobiological calculation method. Wang et al. proposed a new Roots pump profile [10], which is formed by an elliptical arc and a conjugate arc, and can increase the area efficiency. A method for generating the gear teeth profile via complex algebra was established by Laczik et al. [11], and can be used to design the Roots pump. Hsieh [12] also established a profile generation method for rotary lobe pumps via elliptical roulette.

In studies of Roots pump performance, in addition to traditional experimental methods, simulation methods have become more widely used. Maqsood et al. [13] designed an experiment to test the performance of an indigenously developed Roots pumping system; the results show that the performance of the pump system is in line with the expectation. Jou and Huang [14] designed a measurement system for Roots blowers following the SAE J1723 standard, in which the flow rate, temperatures, pressures, and moments can be measured and recorded for further analysis. Singh et al. [15] studied the unsteady flow field of a Roots blower experimentally and numerically; several optical visualization methods were adopted and evaluated in the experiment; the experimental results were compared with the simulated calculation results, which confirmed the existence of the three-dimensional unsteady flow field in Roots blowers, and that it can be affected by the clearances. Huang et al. [16] adopted the dynamic mesh technique to construct a three-dimensional unsteady numerical model and study the flow characteristics of three kinds of rotating pumps. Sun et al. $[17,18]$ used different geometric models to conduct simulations of the Roots pump, and found that the three-dimensional, smaller diameter pipes model is more accurate; the two-dimensional model agrees well with the flow rate and the pressure, but does not apply to the velocity field. Zhang et al. [19] proposed a performance degradation model for the leakage of the Roots pump caused by rotor wear, and verified the accuracy of the model with numerical methods. Gordeeva, Demikhov, and Ochkov [20] put forward a calculation method for the Roots vacuum pump performance to pump a vapor-gas mixture, considering the effect of the gas phase on the pumping speed. Casari et al. [21] adopted SCORG as the grid generator and OpenFOAM as the flow solver to carry out simulations on a Roots blower; the characteristics of the flow field and the moments of the rotors were obtained; moreover, the simulation of the oil injection process in the Roots blower was realized by adding the support of the Lagrangian phase in the simulation model.

To improve the performance of Roots pumps, various new structures have been attempted. Hsieh and Deng [22] studied the performance of multistage Roots pumps via simulations, and found that a pump system with parallel connection and varied phase angle performs best. They also [23] conducted the simulations for Roots pumps of cylindrical 
and screw types, and found that the cylindrical pump has better flow capacity, but the screw pump has lower pulsation. Liu et al. [24] established a three-dimensional unsteady numerical model of a Roots pump; the simulation results showed that the spiral-type entrance and outlet contribute to suppress the flow pulsation. Sun et al. [25] added a backflow structure to the Roots pump; their simulation results showed that the structure contributes to decreasing the fluctuation and increasing the efficiency. Roots pumps with gradually varied gaps were studied experimentally and simulated by Li et al. [26]; they found that this was helpful for reducing the pulsation of the radial force. Furthermore, an outlet with gradually expanding size was put forward to suppress the backflow and the flow noise by Cai et al. [27,28]. Vizgalov et al. [29,30] established a mathematical model of a Roots blower working in conjunction with an ejector adapter; their simulations showed increased efficiency.

As a kind of commonly used positive displacement pump, the Roots pump is widely used in vehicles, refrigeration, and other fields. Xing et al. [31] developed a Roots pump for hydrogen recirculation in a fuel cell system, and tested the performance experimentally; the influences of different fluids and condition parameters on the pump's performance were explored; the results show that the performance of the Roots pump integrated in the system is better than that of the pure hydrogen condition in the test, due to the difference in the fluid. Feng et al. [32] established a three-dimensional CFD model of a Roots pump for hydrogen recirculation in fuel cell systems, and carried out simulations considering the mixture of water vapor and nitrogen with hydrogen; the results show that increases in water vapor and nitrogen content contribute to improve the pump's efficiency; finally, they obtained the correlations between the isentropic efficiency and the volumetric efficiency. Degraff et al. [33] added a Kinney vacuum pump skid consisting of a Roots machine and a liquid ring pump to a cryogenic test facility to increase its cooling ability. He et al. [34] designed a compound boosting system for a $2.0 \mathrm{~L}$ four-cylinder engine with a Miller cycle composed of a turbocharger and a Roots-type supercharger; the effects of different system configurations and supercharger sizes on the system performance were studied via experimental and numerical methods, and the optimal layout was determined.

The gas-liquid mixture Roots pump in the semi-closed-cycle power system might operate under different conditions. The rotational speed, fluid properties, and pressure ratio can change over a wide range. The multiphase flow properties and the rotor motion should be considered simultaneously, which has rarely been investigated in previous studies. The feasibility of the gas-liquid mixture Roots pump has been demonstrated, and the flow characteristics were also analyzed in [7]. In this paper, the performance of the Roots pump at different inlet $\mathrm{CO}_{2}$ volume fractions, rotational speeds, and pressure ratios is studied to further explore the suitability of the Roots pump for compressing gas-liquid mixtures. The design method of the Roots pump is first introduced, and the structure and operating parameters are listed in Section 2. A computational model is established for the Roots pump operating with a gas-liquid mixture in Section 3. Section 4 analyzes the flow characteristics of the gas-liquid mixture Roots pump, and the Roots pump's performance under different conditions is then thoroughly discussed.

\section{Problem Formulation}

The exhaust gases are $\mathrm{CO}_{2}$ and water in the applications of the thermal power system for underwater use. The Roots pump is deemed to be applicable to pressurize gas-liquid mixtures [7]. A three-lobe arc profile was selected and the conventional design method for gas Roots pumps was adopted [35]. The working fluids in the Roots pump were $\mathrm{CO}_{2}$ and water. The inlet total pressure and temperature were $0.46 \mathrm{MPa}$ and $365 \mathrm{~K}$, respectively. Table 1 summarizes the main geometric parameters. The rotor profile is depicted in Figure 1. 
Table 1. Design parameters of the Roots pump. Reprinted with permission from ref. [7]. Copyright 2020 Elsevier.

\begin{tabular}{cc}
\hline Parameter & Value \\
\hline$D$ & $0.102 \mathrm{~m}$ \\
$D_{0}$ & $0.064 \mathrm{~m}$ \\
$R_{m}$ & $0.051 \mathrm{~m}$ \\
$R_{g}$ & $0.022 \mathrm{~m}$ \\
$a$ & $0.037 \mathrm{~m}$ \\
$b$ & $0.033 \mathrm{~m}$ \\
$r$ & $0.018 \mathrm{~m}$ \\
$L$ & $0.134 \mathrm{~m}$ \\
$\delta$ & $0.02 \mathrm{~mm}$ \\
\hline
\end{tabular}

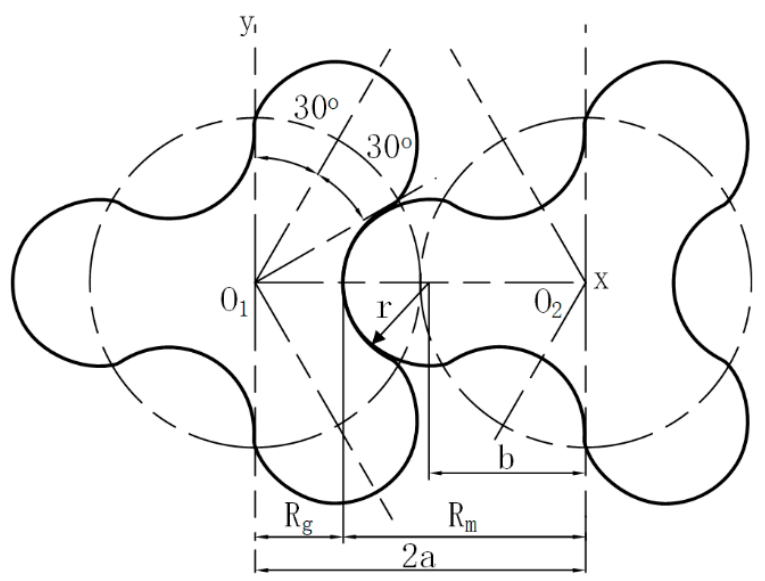

Figure 1. The rotor profile.

The theoretical volume flow rate can be calculated as:

$$
Q_{t h}=\frac{\lambda_{0} \pi n R_{m}^{2} L}{30}
$$

The theoretical volume flow rate can also be calculated as the sum of the gas phase theoretical volume flow rate and the liquid phase theoretical volume flow rate:

$$
Q_{t h}=Q_{l c}+Q_{g c}
$$

The rotor profile is composed of several arcs, defined as:

$$
\begin{gathered}
\left\{\begin{array}{c}
x=b \cos (\pi / Z)+r_{1} \cos \alpha \\
y=b \sin (\pi / Z)+r_{1} \sin \alpha
\end{array} \quad \frac{\pi}{2 Z}<\alpha \leq \frac{\pi}{Z}\right. \\
\left\{\begin{array}{c}
x=2 a \cos \alpha-b \cos 2 \alpha-r_{2}(a \cos \alpha-b \cos 2 \alpha) / \sqrt{a^{2}+b^{2}-2 a b \cos \alpha} \\
y=2 a \sin \alpha-b \sin 2 \alpha+r_{2}(b \sin 2 \alpha-a \sin \alpha) / \sqrt{a^{2}+b^{2}-2 a b \cos \alpha} \quad 0 \leq \alpha<\frac{\pi}{2 Z}
\end{array}\right.
\end{gathered}
$$

The radius of the addendum arc and the dedendum arc, respectively, are:

$$
\begin{aligned}
& r_{1}=r-\delta / 2 \\
& r_{2}=r+\delta / 2
\end{aligned}
$$


To characterize the performance of the Roots pump, the volumetric efficiency, the flow efficiency, and the pump efficiency are defined. The volumetric efficiency can be obtained by dividing the simulated and the theoretical volume flow rate:

$$
\eta_{v}=\frac{Q_{l s}+Q_{g s}}{Q_{t h}}
$$

The flow efficiency is the ratio of the theoretical power to the numerical power. The numerical power is obtained by multiplying the moments and the rotational speed of the rotors. The theoretical power is described as the sum of the gas isothermal compression power and the liquid isometric compression power. Therefore, the flow efficiency is:

$$
\eta_{h}=\frac{\frac{k R_{g} T_{s} m_{g c}}{k-1}\left[\left(\frac{P_{d}}{P_{s}}\right)^{\frac{k-1}{k}}-1\right]+Q_{l c}\left(P_{d}-P_{s}\right)}{M_{1} \omega_{1}+M_{2} \omega_{2}}
$$

The pump efficiency is expressed by the multiplication of the volumetric efficiency and the flow efficiency:

$$
\eta=\eta_{h} \eta_{v}
$$

\section{Computational Model and Validation}

\subsection{Computational Model}

Since the rotor profile is consistent in the axial direction, a two-dimensional model is adopted as the geometric model in the CFD method. The flow domain is depicted in Figure 2. The arrows in the rotors indicate the rotational directions, while the rotational speed of the rotors is identical. The fixed temperature and total pressure are set at the inlet, while the fixed static pressure is specified at the outlet. The user-defined function (UDF) is adopted to obtain the outlet average temperature and then set as the backflow temperature.

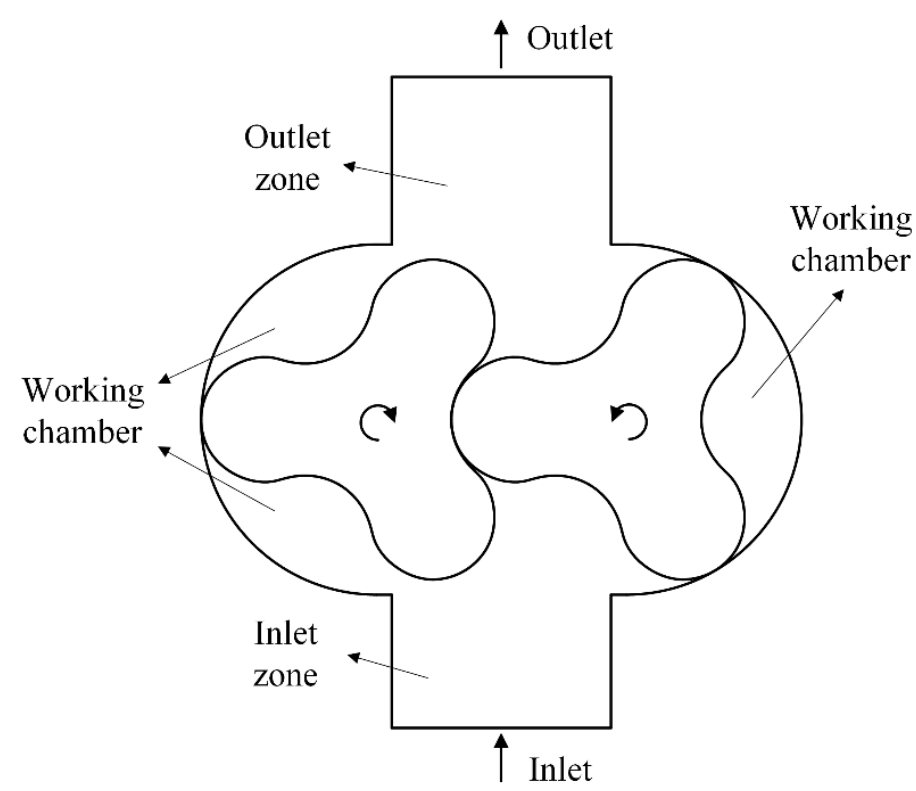

Figure 2. Flow domain of the Roots pump.

The commercial CFD software Fluent 18.0 [36] is used. The flow characteristics in the Roots pump are calculated using the mixture multiphase model. The governing equations are:

Continuity equation:

$$
\frac{\partial}{\partial t}\left(\rho_{h}\right)+\nabla \cdot\left(\rho_{h} \overline{v_{h}}\right)=m_{\&}
$$




$$
\begin{gathered}
\overline{v_{h}}=\frac{\sum_{k=1}^{n} \phi_{k} \rho_{k} \overline{v_{h}}}{\rho_{h}} \\
\rho_{h}=\sum_{k=1}^{n} \phi_{k} \rho_{k}
\end{gathered}
$$

Momentum equation:

$$
\begin{gathered}
\frac{\partial}{\partial t}\left(\rho_{h} \vec{v}_{h}\right)+\nabla \cdot\left(\rho_{h} \vec{v}_{h} \vec{v}_{h}\right)=-\nabla p+\nabla \cdot\left[\mu_{h}\left(\nabla \overrightarrow{v_{h}}+\nabla \vec{v}_{h}^{T}\right)\right]+\rho_{h} \vec{g}+\vec{F}+\nabla \cdot\left(\sum_{k=1}^{n} \phi_{k} \rho_{k} \overrightarrow{v_{d r}, k} \overrightarrow{v_{d r}, k}\right) \\
\mu_{h}=\sum_{k=1}^{n} \phi_{k} \mu_{k} \\
\overrightarrow{v_{d r, k}}=\overrightarrow{v_{k}}-\overrightarrow{v_{h}}
\end{gathered}
$$

Energy equation:

$$
\begin{gathered}
\frac{\partial}{\partial t} \sum_{k=1}^{n}\left(\phi_{k} \rho_{k} E_{k}\right)+\nabla \cdot \sum_{k=1}^{n}\left[\phi_{k} \vec{v}_{k}\left(\rho_{k} E_{k}+p\right)\right]=\nabla \cdot\left(k_{e f f} \nabla T\right)+S_{E} \\
E_{k}=h_{k}-\frac{p}{\rho_{k}}+\frac{v_{k}^{2}}{2}
\end{gathered}
$$

The SST k- $\omega$ model is employed for turbulence closure, which combines the advantages of the $k-\varepsilon$ model in the far field and the $k-\omega$ model in the near-wall region [37]. The PRESTO! method is adopted to discretize the pressure, and the coupled method is adopted to couple the pressure and the velocity. The smoothing and remeshing dynamic mesh methods are employed to update the computational grid at each time step and avoid negative cell volumes. A grid number of 167,221 and a time step of $1 \times 10^{-6} \mathrm{~s}$ are adopted, the independent validations of which were conducted in [7]. The ideal state equation and the Sutherland law for dynamic viscosity are selected for the gas phase, and the constant thermophysical properties are set for the liquid phase.

The limitations of the proposed computational method are as follows:

- The two-dimensional model is adopted in this paper to simplify the simulation, which ignores the axial flow within the Roots pump. By comparing the results from twodimensional and three-dimensional models, [17] concluded that the two-dimensional model is consistent with experimental results in terms of the average parameters and pressure field, but not suitable for the calculation of the velocity field;

- The continuity equation is used in the simulations to describe the characteristics of the fluid, so the aggregation and breakage of the liquid phase cannot be included;

- Though $\mathrm{CO}_{2}$ and water are adopted as the working fluids, the dissolution of $\mathrm{CO}_{2}$ is not considered in the simulations. The $\mathrm{CO}_{2}$ solubility is low at high temperature; otherwise, the operation of the pump blades may cause the $\mathrm{CO}_{2}$ solubility to be less than the theoretical value, as described in [1]. Hence, this assumption is reasonable in the Roots pump simulations.

\subsection{Experimental Validation}

An experimental apparatus was set up to validate the applicability of the simulation model for the gas-liquid mixture Roots pump, as shown in Figure 3. 


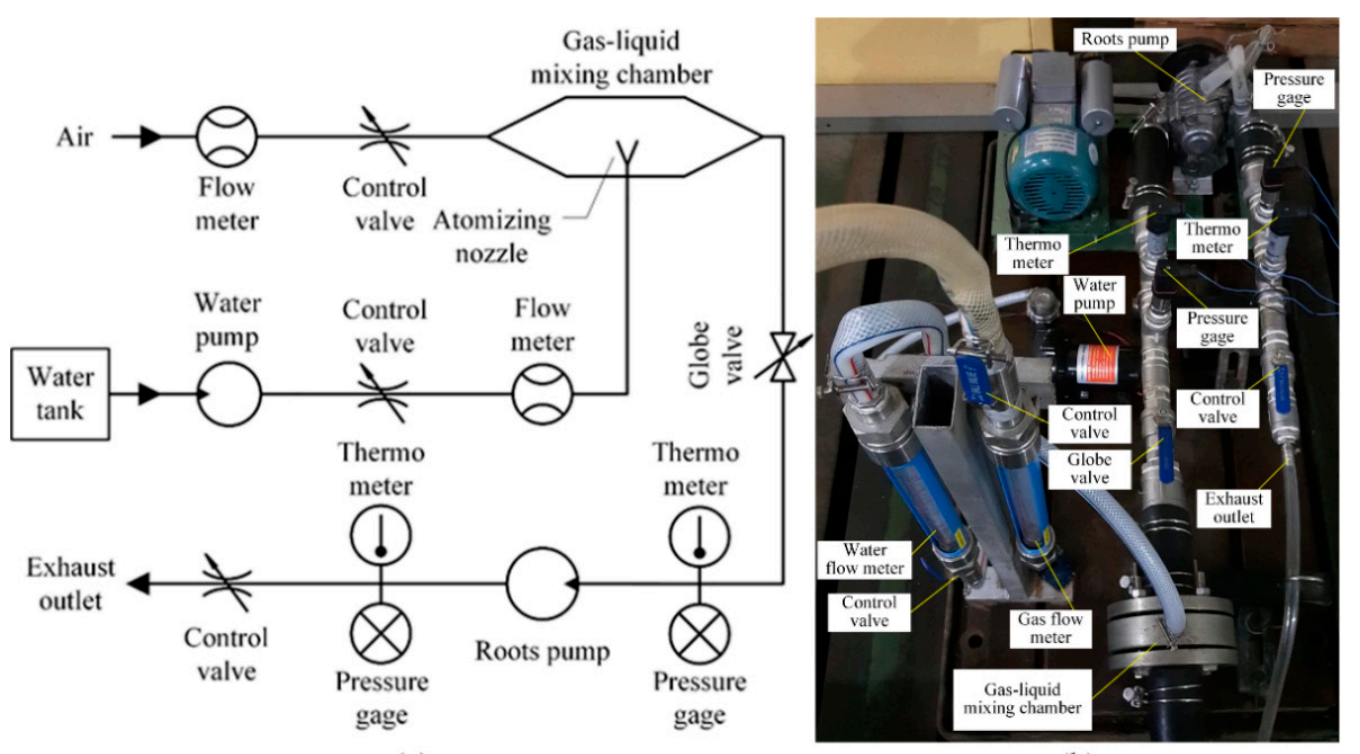

(a)

(b)

Figure 3. Schematic diagram (a) and photograph (b) of the experimental equipment. Reprinted with permission from ref. [7]. Copyright 2020 Elsevier.

Considering the field condition, the gas-liquid mixture in the experiment is generated by mixing the air and water in the gas-liquid mixture chamber. The air comes directly from the atmosphere, and its volumetric flow rate can be measured by the gas flow meter and controlled by the valve. The control valve is installed behind the flow mater to prevent the pressure drop from affecting the measurement of the volumetric flow rate. The water is pumped into the experimental equipment from a specially prepared water tank. The volumetric flow rate can be measured by the water flow meter and adjusted by the control valve. The water is then injected into the gas-liquid mixture chamber via a nozzle and mixed with the air.

The tested Roots pump is a supercharger manufactured by Aisin (the model number is AMR 300). When operating, the gas-liquid mixture flows into the pump and is then compressed. The outlet pressure can be adjusted by the control valve behind the Roots pump. The pressures and temperatures at the inlet and outlet of the pump were recorded to evaluate the performance of the Roots pump. The measured range and accuracy of the instruments in the experimental equipment are shown in Table 2.

Table 2. Measured ranges and accuracy of the instruments in the experimental equipment.

\begin{tabular}{ccc}
\hline Instrument & Measuring Range & Accuracy \\
\hline Gas flow meter & $0.8 \sim 8 \mathrm{~m}^{3} / \mathrm{h}$ & $\pm 0.108 \mathrm{~m}^{3} / \mathrm{h}$ \\
Water flow meter & $63 \sim 630 \mathrm{~L} / \mathrm{h}$ & $\pm 8.505 \mathrm{~L} / \mathrm{h}$ \\
Pressure transducer & $0 \sim 0.5 \mathrm{MPa}$ & $\pm 1250 \mathrm{~Pa}$ \\
Temperature transducer & $0 \sim 100^{\circ} \mathrm{C}$ & $\pm 0.2^{\circ} \mathrm{C}$ \\
Tachograph & $2.5 \sim 999.9 \mathrm{PRM}$ & $\pm 0.5 \mathrm{RPM}$ \\
\hline
\end{tabular}

The uncertainties of the measured parameters should be calculated. For a direct measurement parameter $x$ that has been measured $n$ times, the type-A standard uncertainty can be calculated by:

$$
\mu_{A}=\frac{S(x)}{\sqrt{n}}
$$

The type-B standard uncertainty can be calculated by:

$$
\mu_{B}=\alpha / k_{\alpha}
$$


When the measured parameter is uniformly distributed with probability 1 , the confidence factor is 1.73 .

For an indirect measurement parameter $y$, the combined standard uncertainty can be calculated by:

$$
\mu_{C}(y)=\sqrt{\sum_{i=1}^{N} \mu_{i}^{2}}
$$

The extended uncertainty of the parameter is:

$$
U=k_{\alpha} \mu_{c}
$$

For the simulation, a two-dimensional model was adopted, and the settings were consistent with the content in Section 3.1. The AMR 300 Roots pump has a two-lobe cycloid profile. The gaps between rotors and the cylinder were widened to $0.13 \mathrm{~mm}$ to ensure a stable leakage, considering that the gaps in the axial direction are ignored. The pressures and temperatures at the inlet and the outlet were set to the same as the experimental values. The rotational speed of the rotors, which is set by a UDF, was also the same as in the experiment. Table 3 shows the measured values of the experiment.

Table 3. Measured values in the conditions of the experiment. Reprinted with permission from ref. [7]. Copyright 2020 Elsevier.

\begin{tabular}{ccccc}
\hline Condition Number & $\mathbf{1}$ & $\mathbf{2}$ & $\mathbf{3}$ & $\mathbf{4}$ \\
\hline Rotational speed $(\mathrm{rpm})$ & 800 & 801 & 798 & 796 \\
Averaged gas mass flow rate $(\mathrm{g} / \mathrm{s})$ & 0.99 & 1.32 & 1.65 & 1.98 \\
Averaged water mass flow rate $(\mathrm{kg} / \mathrm{s})$ & 0.14 & 0.14 & 0.14 & 0.14 \\
Averaged inlet pressure $(\mathrm{Pa})$ & 35,594 & 43,156 & 51,875 & 64,469 \\
Averaged outlet pressure $(\mathrm{Pa})$ & 141,156 & 148,781 & 164,375 & 177,438 \\
Averaged inlet temperature $(\mathrm{k})$ & 289.6 & 289.7 & 289.8 & 289.5 \\
Averaged outlet temperature $(\mathrm{k})$ & 290.0 & 290.0 & 289.9 & 289.7 \\
\hline
\end{tabular}

The flow efficiency, the volumetric efficiency, and the pump efficiency of the simulations and the experiment were compared, as shown in Figure 4. The relative errors of the efficiency between the simulations and the experiment were less than $7 \%$. Although some numerical results were not within the extended uncertainties of the experiment, the differences are acceptable in practice.

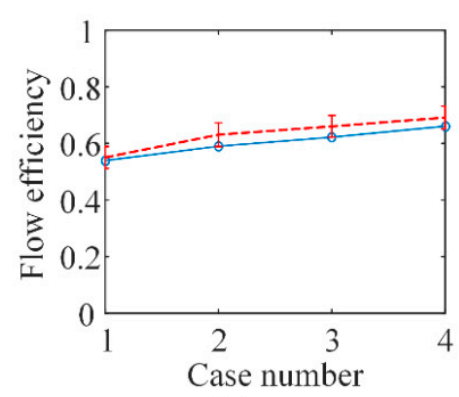

(a)

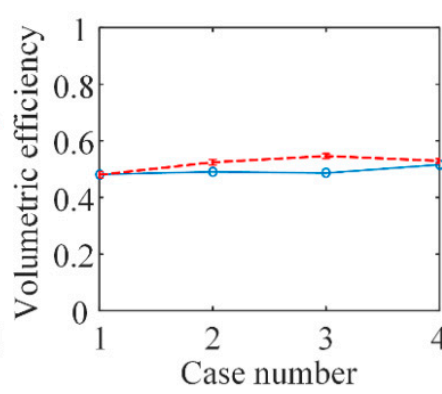

(b)

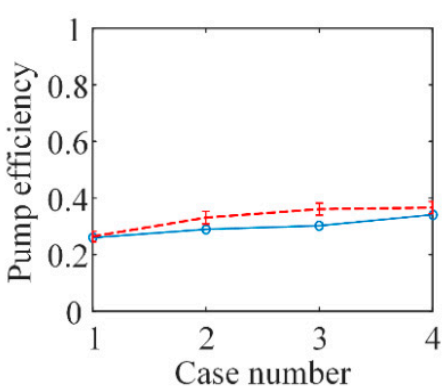

(c)

$$
\text { - Numerical - - - Experiment }
$$

Figure 4. Efficiencies between the simulations and the experiment. (a) flow efficiency; (b) volumetric efficiency; (c) pump efficiency. Reprinted with permission from ref. [7]. Copyright 2020 Elsevier.

The result of the experimental validation indicates that the current numerical model and settings can be used to predict the performance of gas-liquid mixture Roots pumps. 


\section{Results and Discussion}

\subsection{Effect of Inlet $\mathrm{CO}_{2}$ Volume Fraction}

When the underwater power system operates under different conditions, the mass flow rate of the exhaust gas and the required cooling water alters, resulting in a change in the gas volume fraction. Numerical simulations under different inlet $\mathrm{CO}_{2}$ volume fractions were performed to study the influence of the gas volume fraction. Here, the inlet $\mathrm{CO}_{2}$ volume fraction changed from 0.8 to 1 by considering the operating range of the thermal power system. The rotational speed of the Roots pump was $2500 \mathrm{rpm}$, the pressure ratio was 2 , and other parameters are shown in Table 4.

Table 4. Operating conditions with various inlet $\mathrm{CO}_{2}$ volume fractions.

\begin{tabular}{ccccc}
\hline Case Numbers & Inlet Pressure & Outlet Pressure & Rotational Speed & $\begin{array}{c}\text { Inlet } \mathrm{CO}_{2} \\
\text { Volume Fraction }\end{array}$ \\
\hline 1 & & & 0.80 \\
2 & & & & 0.90 \\
3 & $0.46 \mathrm{MPa}$ & $0.92 \mathrm{MPa}$ & $2500 \mathrm{rpm}$ & 0.95 \\
4 & & & 0.99 \\
5 & & & 1.00 \\
\hline
\end{tabular}

The corresponding efficiencies are depicted in Figure 5. The volumetric efficiency increases from $92 \%$ to $97 \%$, and then decreases to $80 \%$, when the volume fraction is larger than 0.9. Meanwhile, the flow efficiency shows an increased trend under the investigated conditions. The pump efficiency maintains an upward trend from $48 \%$ to $64 \%$ and then drops to $59 \%$ for pure $\mathrm{CO}_{2}$.

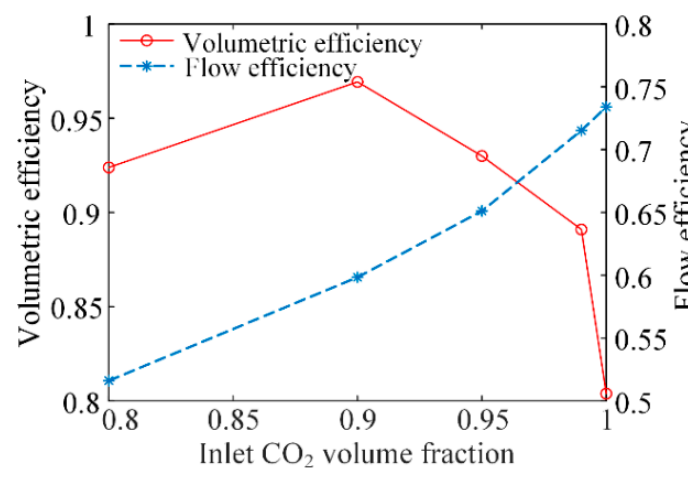

(a)

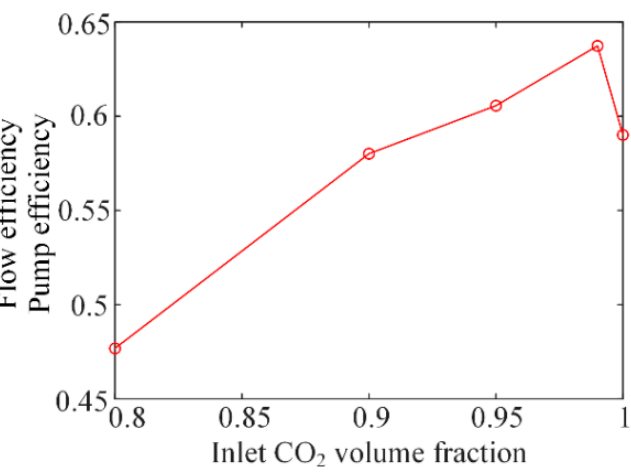

(b)

Figure 5. Efficiencies at different inlet $\mathrm{CO}_{2}$ volume fractions. (a) volumetric efficiency and flow efficiency; (b) pump efficiency.

To explain this variation, the flow characteristics first need to be explored. For threelobe Roots pumps, the theoretical pulsation period is the time that the rotors take to rotate 120 degrees ( $0.008 \mathrm{~s}$ when the rotational speed is $2500 \mathrm{rpm}$ ). The time that the rotors take to rotate 60 degrees $(0.004 \mathrm{~s}$ when the rotational speed is $2500 \mathrm{rpm}$ ) is long enough to show the transient variation of the flow field, taking the conjugacy of the pump into account. Figures 6 and 7 depict the pressure streamline contours and the water volume fraction contours when the inlet $\mathrm{CO}_{2}$ volume fraction is 0.8 . 


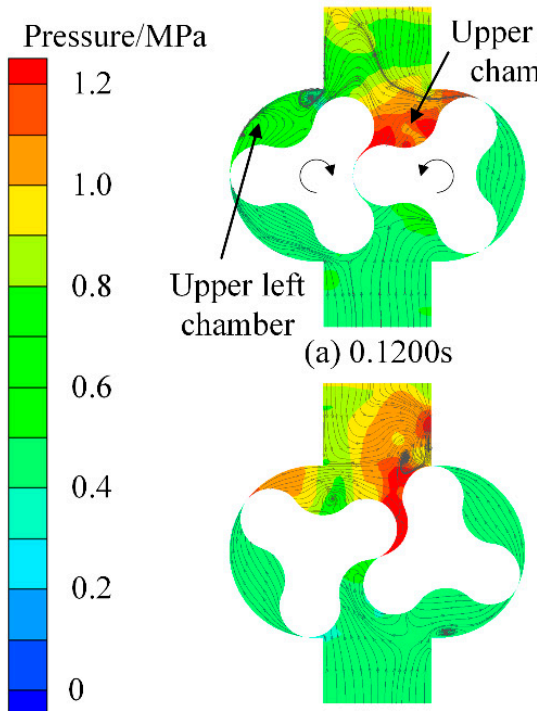

(d) $0.1224 \mathrm{~s}$

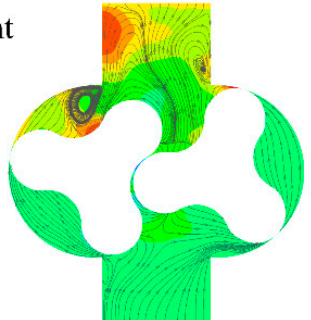

(b) $0.1208 \mathrm{~s}$

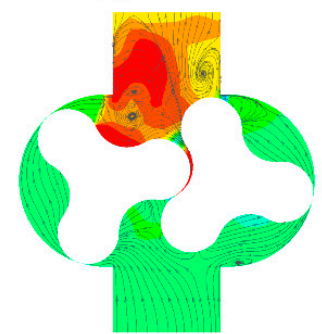

(e) $0.1232 \mathrm{~s}$

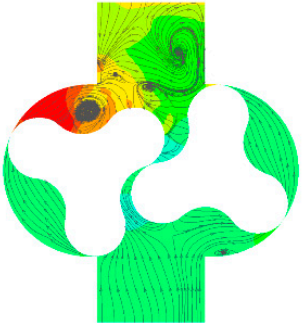

(c) $0.1216 \mathrm{~s}$

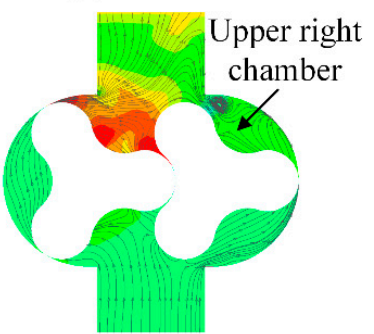

(f) $0.1240 \mathrm{~s}$

Figure 6. Pressure streamline contours of the Roots pump when the inlet $\mathrm{CO}_{2}$ volume fraction is 0.8 . Flow time: (a) $0.1200 \mathrm{~s}$; (b) $0.1208 \mathrm{~s}$; (c) $0.1216 \mathrm{~s}$; (d) $0.1224 \mathrm{~s}$; (e) $0.1232 \mathrm{~s}$; (f) $0.1240 \mathrm{~s}$.

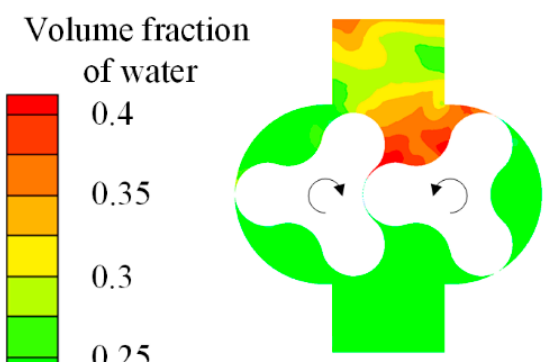

(a) $0.1200 \mathrm{~s}$

0.2

0.15

0.1

0.05

0

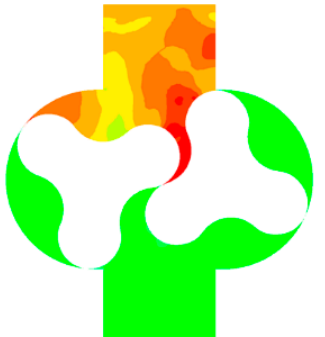

(d) $0.1224 \mathrm{~s}$

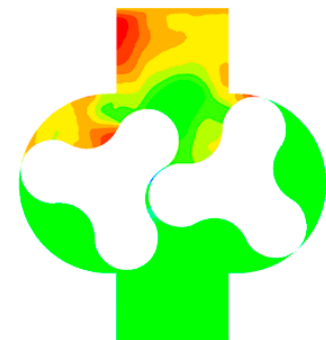

(b) $0.1208 \mathrm{~s}$

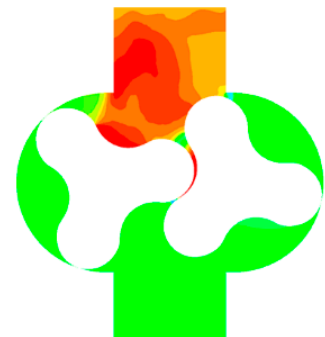

(e) $0.1232 \mathrm{~s}$

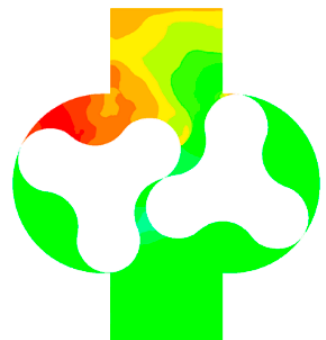

(c) $0.1216 \mathrm{~s}$

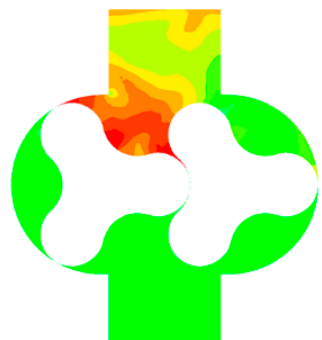

(f) $0.1240 \mathrm{~s}$

Figure 7. Water volume fraction contours of the Roots pump when the inlet $\mathrm{CO}_{2}$ volume fraction is 0.8 . Flow time: (a) $0.1200 \mathrm{~s}$; (b) $0.1208 \mathrm{~s}$; (c) $0.1216 \mathrm{~s}$; (d) $0.1224 \mathrm{~s}$; (e) $0.1232 \mathrm{~s}$; (f) $0.1240 \mathrm{~s}$.

The rotation and the backflow result in the compression of the fluid, as shown in Figure 6 . Due to the suction effect caused by the volume change at the inlet zone, the working fluid flows into the inlet zone. The pressure in the inlet zone remains constant, since the fluid is not compressed in this process. During the rotation, the closed working chamber is generated. Then, the gas-liquid mixture in the inlet zone is transported to the outlet zone. The volume of the chamber remains constant during the transportation process, and the gas-liquid mixture inside is compressible. Therefore, the pressure within the working chamber does not change significantly. When the working chamber continues to move and connects to the outlet zone, the backflow, whose pressure is high, flows into the outlet, increasing the local pressure. The working fluid is finally pressurized and pumped out of the Roots pump together with the backflow, resulting in a decrease in pressure. 
To further study the flow characteristics in the outlet zone, as shown in Figure 6a,b, the upper-left chamber begins to connect to the outlet zone, while the upper-right chamber is about to disappear. Part of the compressed fluid in it flows into the upper-left chamber, mixing with the working fluid; therefore, the local pressure is increased. The rest of the fluid flows out of the outlet. In Figure $6 c$, the upper-right chamber gradually disappears and the volume of the upper-left chamber decreases. The pressure in the outlet zone is lower than that of the outlet boundary, leading to the backflow. The pressure in the upper-left chamber continues to increase, due to the backflow and the extrusion of the left rotor. In Figure 6d, the upper-left chamber is now completely connected to the outlet zone. The compressed working fluid in the upper-left chamber flows into the outlet zone and mixes with the backflow, resulting in the increased outlet zone pressure. As shown in Figure 6e, the pressure in the outlet zone continues to increase, and a new upper-right chamber begins to connect to the outlet zone. Finally, the flow field nearly conjugates with the initial state, as shown in Figure $6 \mathrm{f}$.

Comparing Figures 6 and 7, the variation in the pressure and water volume fraction is similar. This can be explained by the physical properties of the gas-liquid mixture. The liquid phase is incompressible, while the gas phase is compressible. When the pressure in the domain increases, the gas phase is compressed and the volume decreases, resulting in an increase in the water volume fraction. This phenomenon implies that the main factor affecting the gas-liquid distribution is the compression effect of the pressure in the operation of the gas-liquid mixture Roots pump.

A similar flow pattern is also obtained under the working conditions when the inlet $\mathrm{CO}_{2}$ volume fraction is $0.9,0.95,0.99$, and 1 , as shown in Figures 8-11, respectively. In the inlet zone, the pressure remains constant, while the pressure in the outlet zone fluctuates periodically. A local pressure higher than the outlet pressure is formed intermittently in the outlet zone and the working chambers, due to the backflow and the extrusion of the rotors. Figure 12 illustrates the pressure variation at the outlet. It can be seen that both the frequency and the amplitude are varied at different operating conditions.

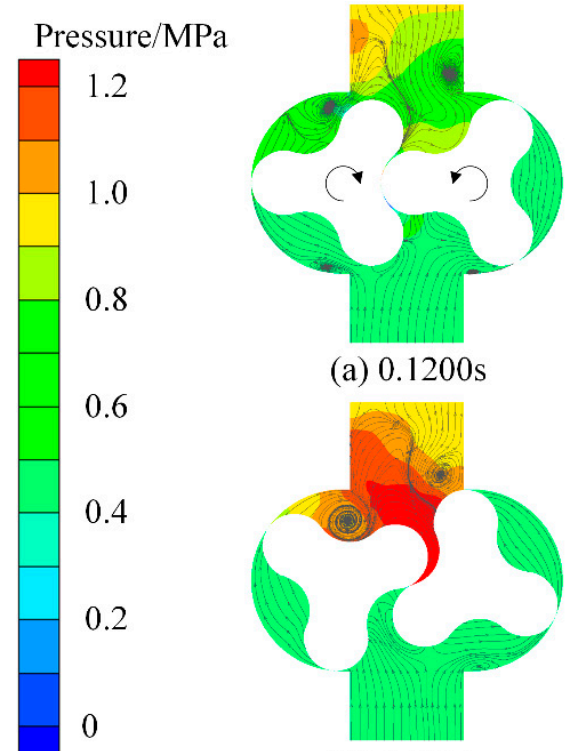

(d) $0.1224 \mathrm{~s}$

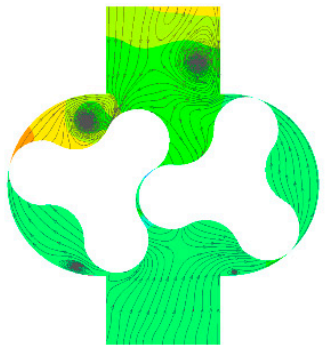

(b) $0.1208 \mathrm{~s}$

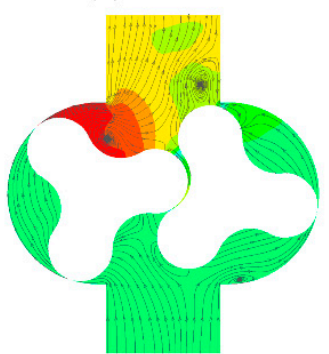

(e) $0.1232 \mathrm{~s}$

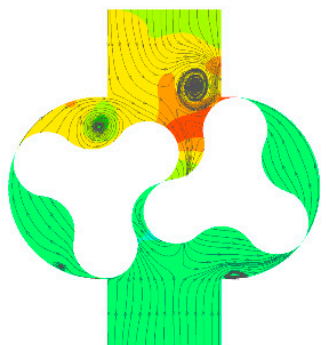

(c) $0.1216 \mathrm{~s}$

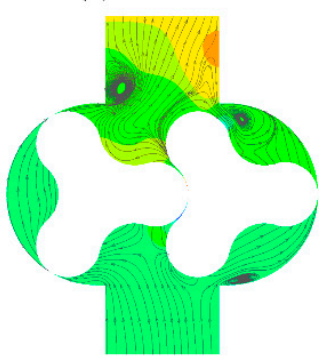

(f) $0.1240 \mathrm{~s}$

Figure 8. Pressure streamline contours of the Roots pump when the inlet $\mathrm{CO}_{2}$ volume fraction is 0.9. Flow time: (a) $0.1200 \mathrm{~s}$; (b) $0.1208 \mathrm{~s}$; (c) $0.1216 \mathrm{~s}$; (d) $0.1224 \mathrm{~s}$; (e) $0.1232 \mathrm{~s}$; (f) $0.1240 \mathrm{~s}$. 


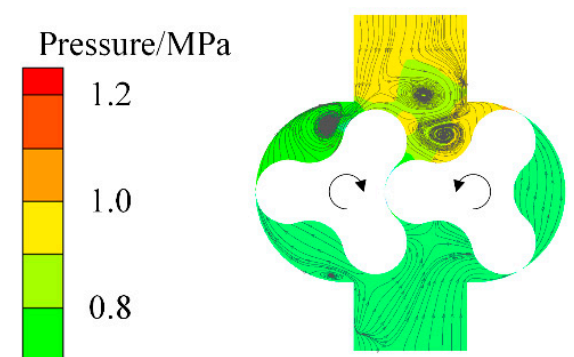

(a) $0.1200 \mathrm{~s}$

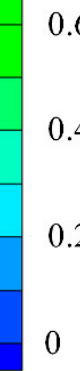

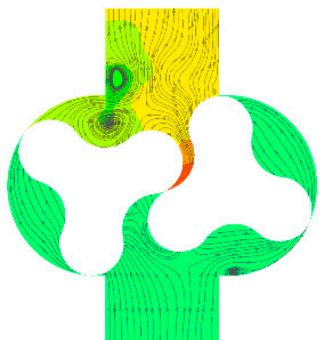

(d) $0.1224 \mathrm{~s}$

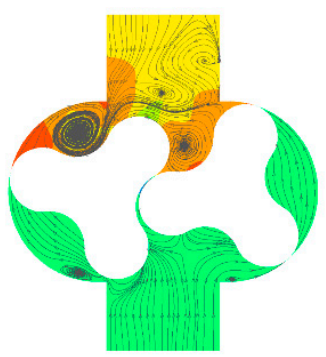

(b) $0.1208 \mathrm{~s}$

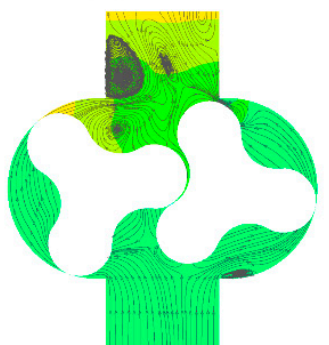

(e) $0.1232 \mathrm{~s}$

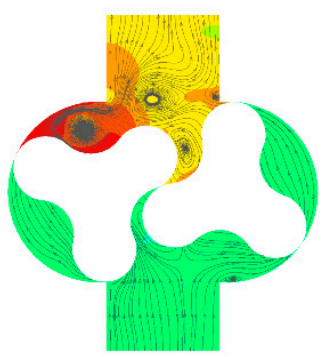

(c) $0.1216 \mathrm{~s}$

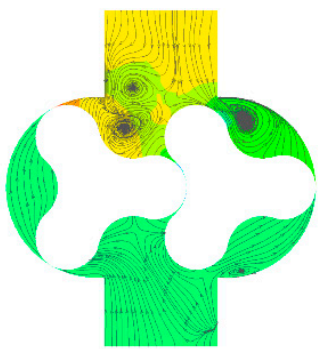

(f) $0.1240 \mathrm{~s}$

Figure 9. Pressure streamline contours of the Roots pump when the inlet $\mathrm{CO}_{2}$ volume fraction is 0.95 . Flow time: (a) $0.1200 \mathrm{~s}$; (b) $0.1208 \mathrm{~s}$; (c) $0.1216 \mathrm{~s}$; (d) $0.1224 \mathrm{~s}$; (e) $0.1232 \mathrm{~s}$; (f) $0.1240 \mathrm{~s}$.

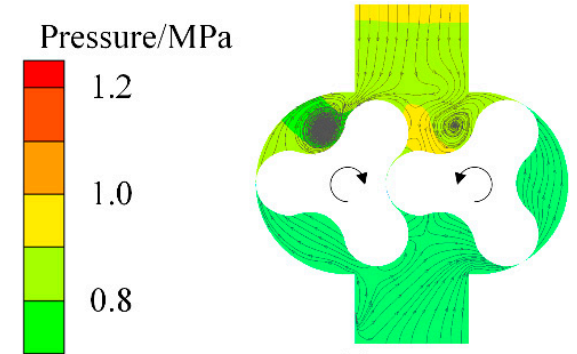

(a) $0.1200 \mathrm{~s}$

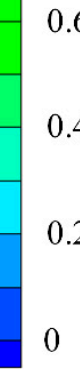

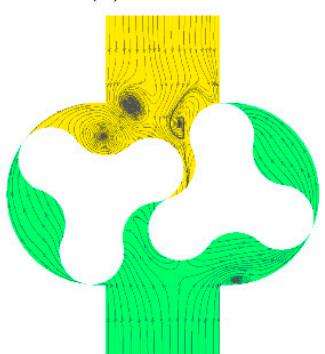

(d) $0.1224 \mathrm{~s}$

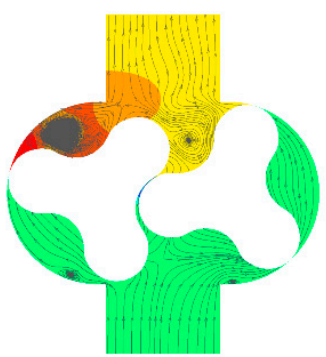

(b) $0.1208 \mathrm{~s}$

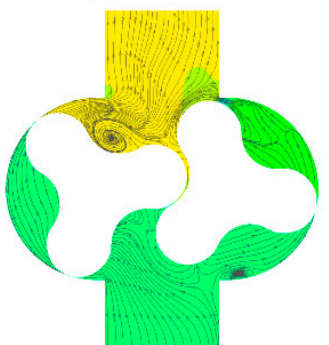

(e) $0.1232 \mathrm{~s}$

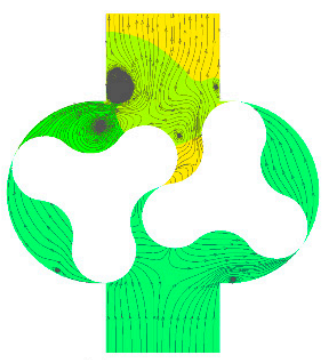

(c) $0.1216 \mathrm{~s}$

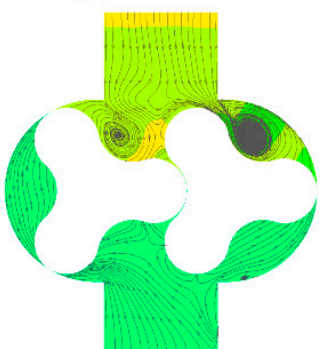

(f) $0.1240 \mathrm{~s}$

Figure 10. Pressure streamline contours of the Roots pump when the inlet $\mathrm{CO}_{2}$ volume fraction is 0.99 . Flow time: (a) $0.1200 \mathrm{~s}$; (b) $0.1208 \mathrm{~s}$; (c) $0.1216 \mathrm{~s}$; (d) $0.1224 \mathrm{~s}$; (e) $0.1232 \mathrm{~s}$; (f) $0.1240 \mathrm{~s}$.

The increased inlet $\mathrm{CO}_{2}$ volume fraction tends to reduce the pressure amplitude (see in Figure 12). The pressure pulsation amplitude is larger than $0.26 \mathrm{MPa}$ at the outlet for the inlet $\mathrm{CO}_{2}$ volume fraction of 0.8 , while the maximum pressure is larger than $2 \mathrm{MPa}$ at the outlet zone. When the inlet $\mathrm{CO}_{2}$ volume fraction changes to 0.9 , the amplitude of the outlet pressure decreases to $0.2 \mathrm{MPa}$, and the maximum pressure also decreases to $1.8 \mathrm{MPa}$. As the inlet $\mathrm{CO}_{2}$ volume fraction continues to increase, the pressure amplitude at the outlet drops to less than $0.1 \mathrm{MPa}$. The maximum pressure in the Roots pump is $1.5 \mathrm{MPa}$ when the inlet $\mathrm{CO}_{2}$ volume fraction is 0.95 , and $1.26 \mathrm{MPa}$ at an inlet $\mathrm{CO}_{2}$ volume fraction of 0.99 . When pure $\mathrm{CO}_{2}$ is prescribed, the pressure pulsation disappears almost entirely, and the maximum pressure decreases to $1 \mathrm{MPa}$. 


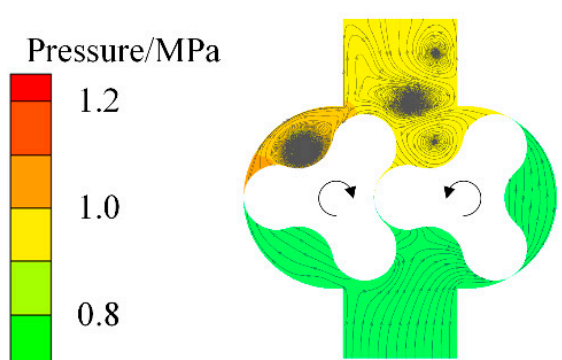

(a) $0.1200 \mathrm{~s}$

0.6

0.4

0.2

0

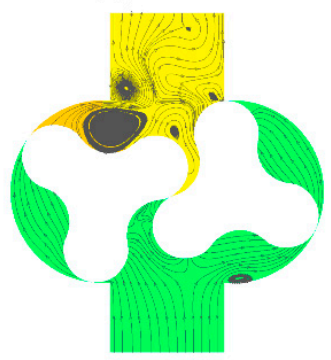

(d) $0.1224 \mathrm{~s}$

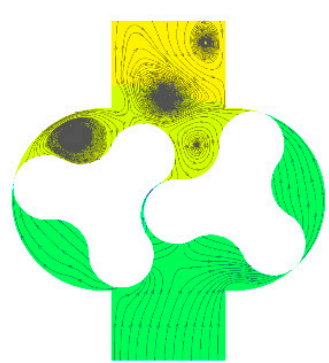

(b) $0.1208 \mathrm{~s}$

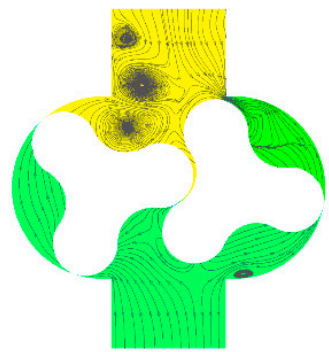

(e) $0.1232 \mathrm{~s}$

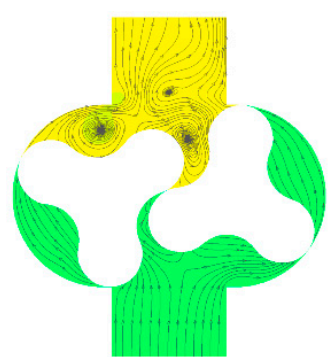

(c) $0.1216 \mathrm{~s}$

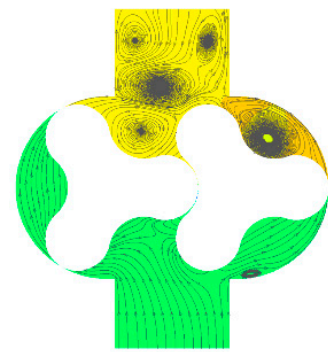

(f) $0.1240 \mathrm{~s}$

Figure 11. Pressure streamline contours of the Roots pump when the inlet $\mathrm{CO}_{2}$ volume fraction is 1 . Flow time: (a) $0.1200 \mathrm{~s}$; (b) $0.1208 \mathrm{~s}$; (c) $0.1216 \mathrm{~s}$; (d) $0.1224 \mathrm{~s}$; (e) $0.1232 \mathrm{~s}$; (f) $0.1240 \mathrm{~s}$.

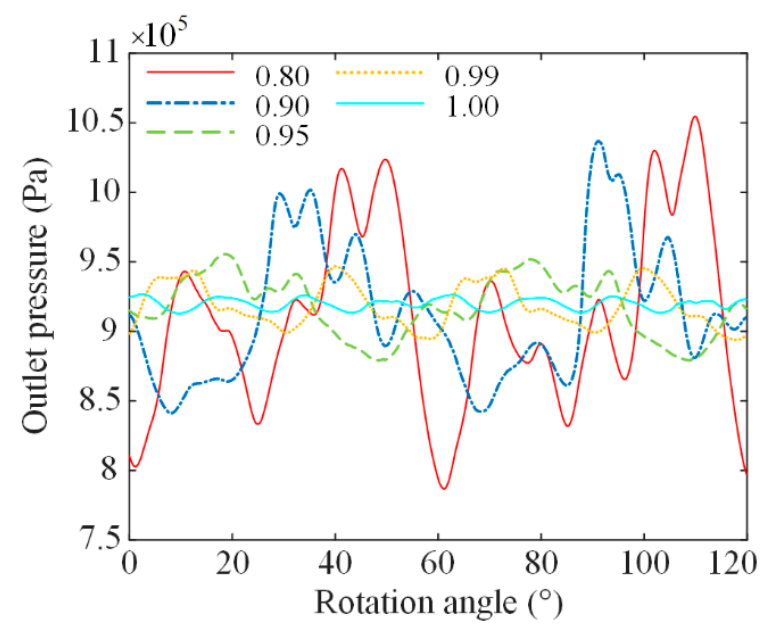

Figure 12. Curves of the variation of the outlet pressure of the Roots pump under different inlet $\mathrm{CO}_{2}$ volume fractions.

The frequency of the pressure pulsation at the outlet is also discussed. When the inlet fluid is pure $\mathrm{CO}_{2}$, the outlet pressure pulsates four times in the time it takes for the rotors to rotate 60 degrees. This pulse number decreases to two when the inlet $\mathrm{CO}_{2}$ volume fraction is 0.99 . When the inlet $\mathrm{CO}_{2}$ volume fraction decreases to 0.95 or 0.9 , the outlet pressure pulsates once per 60-degree rotation of the rotors. The pulse number of the outlet pressure is also one when the inlet $\mathrm{CO}_{2}$ volume fraction is 0.8 , while two peaks with different values exist in each pulsation.

The differences in the flow characteristics can be attributed to the fluid properties resulting from different volume fractions. The pressure difference overcomes the inertia and pushes the gas-liquid mixture flow out of the pump. The incompressible liquid phase has the characteristics of high density and large inertia, while the gas phase is compressible and is characterized as having low density and inertia. When the inlet $\mathrm{CO}_{2}$ volume fraction is low, the density and the inertia of the compressible gas-liquid mixture are relatively high. The high pressure difference is needed to push the fluid flow out of the pump, which results in the prolonged and high-intensity backflow. Meanwhile, the local pressure 
fluctuation is created in the outlet zone. Therefore, the high-amplitude and low-frequency pressure pulsation flow is formed, and multiple pulsation peaks may appear under some working conditions. The density and the inertia of the gas-liquid mixture decrease with the increase in the inlet $\mathrm{CO}_{2}$ volume fraction, resulting in a decrease in the pressure pulsation amplitude and an increase in the frequency at the outlet.

The volumetric efficiency is mainly determined by the leakage, and the leakage is determined by the properties of the fluid and the pressure difference between the inlet and the outlet. To further study the influence of the gas volume fraction and the pressure difference on the leakage, a two-dimensional model of the gap between the rotor and the casing was established, as shown in Figure 13. The rotor rotation is not considered in the simulation. The node number of the mesh is 18,436 in order to ensure that the wall $y+$ number is less than 2 . The simulation settings were set according to the method described in Section 3.1. The flow direction of the gas-liquid mixture is from the outlet zone to the inlet zone, so the pressure was set as $0.46 \mathrm{MPa}$ at the pressure outlet, and the temperature was $365 \mathrm{~K}$. The pressure ratio was from 1.5 to 4 and the gas volume fraction was from 0.8 to 1 under different working conditions.

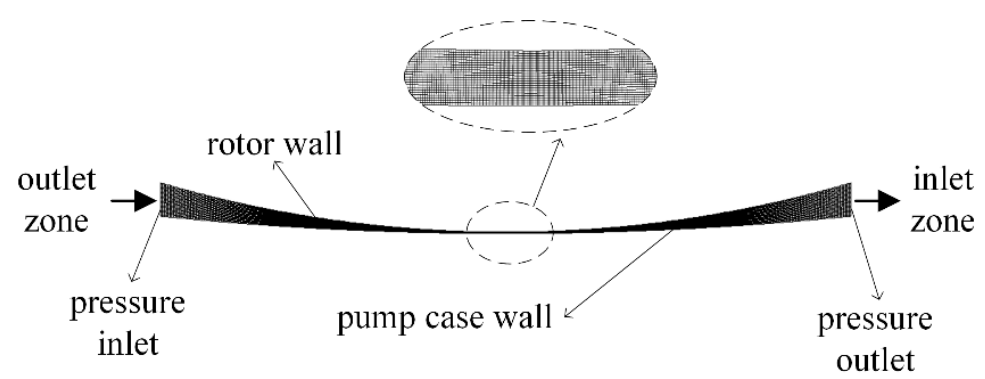

Figure 13. Two-dimension model of the gap between the rotor and the case (not to scale).

Figure 14 shows the pressure, velocity, and water volume fraction contours when the pressure ratio is 2 and the $\mathrm{CO}_{2}$ volume fraction at the inlet zone is 0.8 . As shown in Figure 14a, the pressure decreases from the pressure inlet to the pressure outlet, while the lowest pressure occurs at the accessory with the smallest clearance. Meanwhile, the pressure changes are not uniform in the region close to the pressure outlet; this is caused by the variation of the velocity. As shown in Figure 14b, the fluid gradually accelerates, and reaches a maximum value at the minimum clearance as the gap decreases. The highvelocity fluid then flows into the region close to the pressure outlet and mixes with the low-velocity fluid within it. The increase in the velocity represents an increase in the dynamic pressure, which leads to a decrease in the static pressure. As shown in Figure 14c, the variation of the water volume fraction is similar to that of the pressure. This further indicates that the change in the volume fraction is mainly caused by the compression of the gas phase.

Figure 15 shows the leakage volume flow rates under different conditions. With the decrease in the inlet zone gas volume fraction, the leakage volume flow rate decreases accordingly, and the rate of decrease becomes smaller. This indicates that the presence of the liquid phase is beneficial in terms of sealing the gaps. A similar phenomenon can be found in the comparison of the cases with different pressure ratios. The high pressure ratio leads to a large amount of leakage, while the leakage increment decreases as the pressure ratio increases. The gas volume fraction presents a larger influence on the leakage than the pressure ratio. 


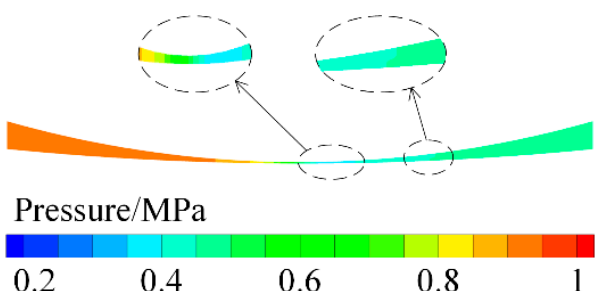

(a)

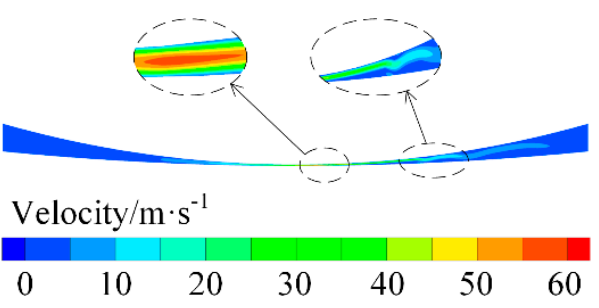

(b)

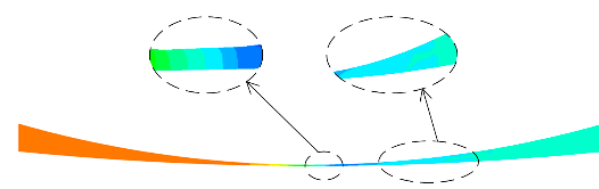

Water volume fraction

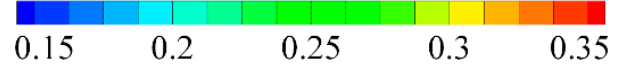

(c)

Figure 14. Pressure, velocity, and water volume fraction contours under the conditions of a pressure ratio of 2 and an inlet $\mathrm{CO}_{2}$ volume fraction of 0.8 (not in scale). (a) pressure contours; (b) velocity contours; (c) water volume fraction contours.

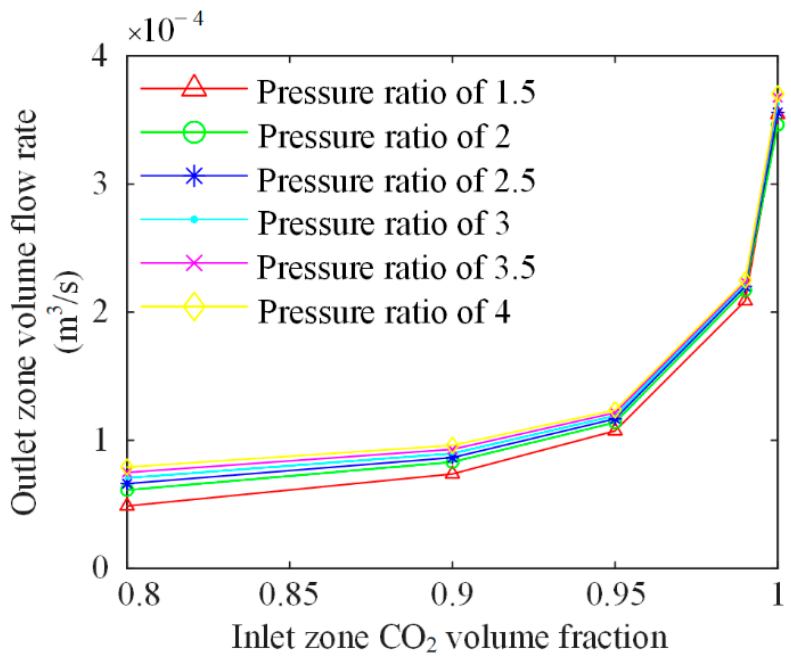

Figure 15. Leakage volume flow rates under different gas volume fractions and pressure ratios.

To summarize, the leakage in the Roots pump is jointly influenced by the gas volume fraction in the pump and the pressure difference between the inlet and the outlet zones. With the decrease in the gas volume fraction, the sealing effectiveness of the gaps improves, leading to a decrease in the leakage. Meanwhile, with the increased pressure difference between the inlet and the outlet zones, the driving force of the flow in the gaps increases and the leakage rises. In addition, the relatively low gas volume fraction in the pump leads to the high local pressure in the outlet zone, increasing the pressure difference between the inlet zone and the outlet zone. Hence, the pressure difference is dominant, leading to leakage when the inlet $\mathrm{CO}_{2}$ volume fraction is less than 0.9. In this range, the high local pressure decreases with the increased inlet $\mathrm{CO}_{2}$ volume fraction, reducing the pressure difference and the leakage. As a result, the volumetric efficiency increases. When the inlet $\mathrm{CO}_{2}$ volume fraction is larger than 0.9 , the key factor affecting the leakage switches to the gas volume fraction in the pump. In this case, the sealing effectiveness of the gaps is weakened with the increased inlet $\mathrm{CO}_{2}$ volume fraction, decreasing the volumetric efficiency, as shown in Figure 5a.

The flow efficiency is directly determined by the moments of the rotors. Figure 16 shows the simulated total moments and the theoretical total moments in different cases, in 
which the theoretical total moment can be achieved by dividing the theoretical compression power of the pump by the angular velocity of the rotors. The theoretical total moment decreases slightly with the increase in the inlet $\mathrm{CO}_{2}$ volume fraction, which is caused by the difference in compression power between the gas phase and the liquid phase under the same volume. The simulated total moment is larger than the theoretical total moment, and also decreases with the increase in the inlet $\mathrm{CO}_{2}$ volume fraction. The reduction in the simulated total moment is larger than that of the theoretical total moment.

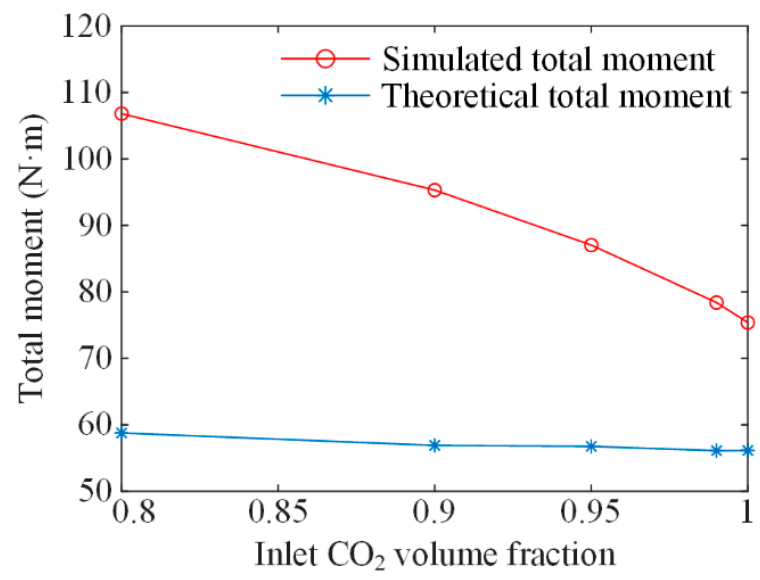

Figure 16. Theoretical and simulated total moment of the Roots pump under different inlet $\mathrm{CO}_{2}$ volume fractions.

The simulated total moments are determined by the difference between the pressure in the inlet zone and the outlet zone. Considering that the pressure in the inlet zone is almost constant, the pressure in the outlet zone is the main factor affecting the rotor moment. The local pressure in the outlet zone is relatively high when the inlet $\mathrm{CO}_{2}$ volume fraction is low, leading to the average pressure being significantly higher than the outlet pressure. This increases the total moment, resulting in a low flow efficiency. With the increase in the inlet $\mathrm{CO}_{2}$ volume fraction, the high local pressure in the outlet zone gradually disappears because of the change in the fluid properties, reducing the average pressure. Therefore, the rotor moment decreases, and the flow efficiency increases.

The pump efficiency is the combination of the volumetric efficiency and the flow efficiency. Therefore, it presents a trend of first rising and then falling with the increased inlet $\mathrm{CO}_{2}$ volume fraction.

\subsection{Effect of Rotational Speed}

The underwater power system can also operate at various speeds. To study the flow characteristics of the Roots pump under different rotational speeds, numerical simulations were conducted with the rotational speeds of $1000 \mathrm{rpm}$ and $4000 \mathrm{rpm}$. The inlet pressure was $0.46 \mathrm{MPa}$, the pressure ratio was 2 , and the inlet $\mathrm{CO}_{2}$ volume fraction was 0.8 . The relevant parameters are shown in Table 5.

Table 5. Setting parameters of simulations with various rotational speeds.

\begin{tabular}{ccccc}
\hline Case Numbers & Inlet Pressure & Outlet Pressure & $\begin{array}{c}\text { Inlet } \mathrm{CO}_{2} \text { Volume } \\
\text { Fraction }\end{array}$ & $\begin{array}{c}\text { Rotational } \\
\text { Speed }\end{array}$ \\
\hline 1 & $0.46 \mathrm{MPa}$ & $0.92 \mathrm{MPa}$ & 0.80 & $1000 \mathrm{rpm}$ \\
2 & & & $2500 \mathrm{rpm}$ \\
\hline
\end{tabular}

The efficiencies at different rotational speeds were obtained, and are shown in Figure 17. 


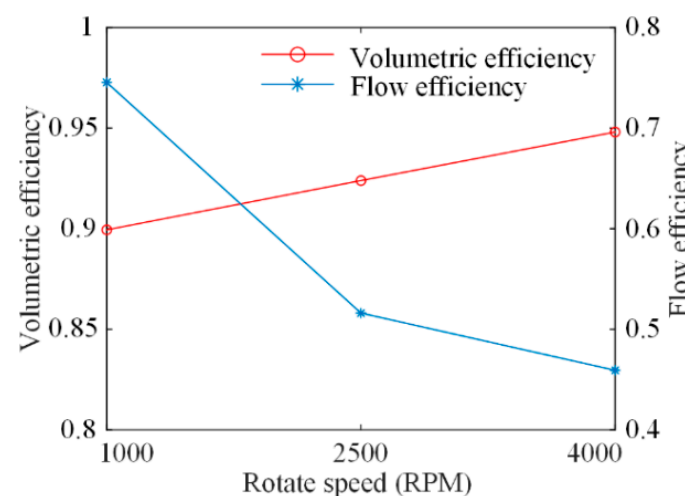

(a)

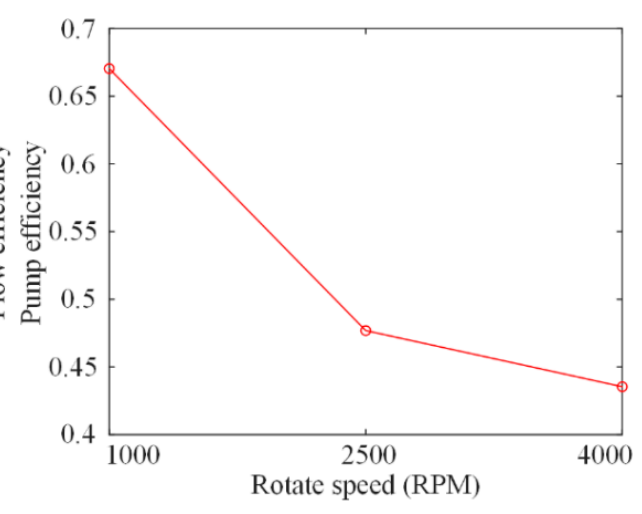

(b)

Figure 17. Efficiencies of the Roots pump under various rotational speeds. (a) volumetric efficiency and flow efficiency; (b) pump efficiency.

When the rotational speed increases from $1000 \mathrm{rpm}$ to $4000 \mathrm{rpm}$, the volumetric efficiency increases from $90 \%$ to $95 \%$, and the flow efficiency decreases from $75 \%$ to $46 \%$, while the pump efficiency decreases from $67 \%$ to $44 \%$. The theoretical volume flow rate increases with the rotational speed. The leakage is mainly determined by the pressure ratio [35]. Therefore, the volumetric efficiency of the Roots pump shows an upward trend when the rotational speed increases.

Figures 18 and 19 show the pressure contours of the Roots pump at different rotational speeds (from $0.3 \mathrm{~s}$ to $0.31 \mathrm{~s}$ of the rotational speed of $1000 \mathrm{rpm}$, and from $0.075 \mathrm{~s}$ to $0.0775 \mathrm{~s}$ of the rotational speed of $4000 \mathrm{rpm}$ ). The maximum pressure in the outlet zone at the speed of $4000 \mathrm{rpm}$ is much higher than that at the speed of $1000 \mathrm{rpm}$. This means that larger moments are applied on the rotors, and a lower flow efficiency is achieved at $4000 \mathrm{rpm}$. The compression process is accomplished by the combined effect of the backflow and the rotation. When the rotational speed is high, the extrusion effect of the backflow and the rotors on the fluid in the pump becomes more intense, making the pressure in the outlet zone significantly exceed the outlet pressure. This increases the moment of the rotors and reduces the flow efficiency when the rotational speed is high.

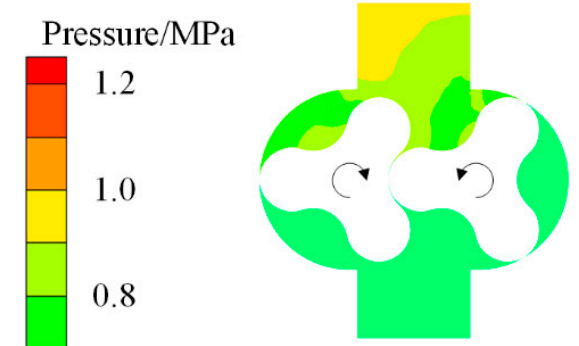

(a) $0.300 \mathrm{~s}$

0.6

0.4

0.2

0

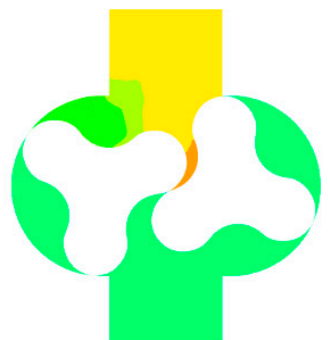

(d) $0.306 \mathrm{~s}$

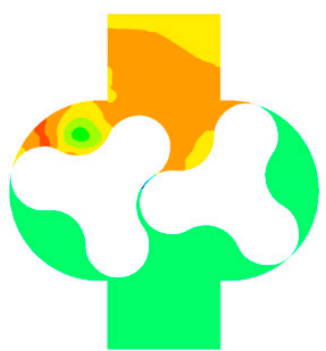

(b) $0.302 \mathrm{~s}$

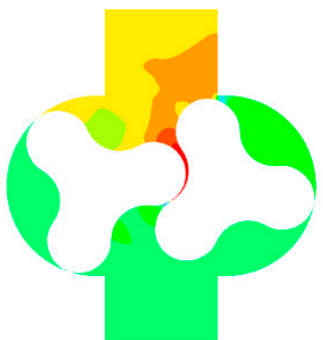

(e) $0.308 \mathrm{~s}$

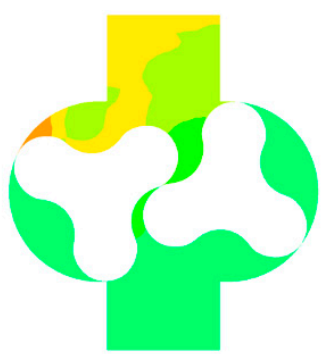

(c) $0.304 \mathrm{~s}$

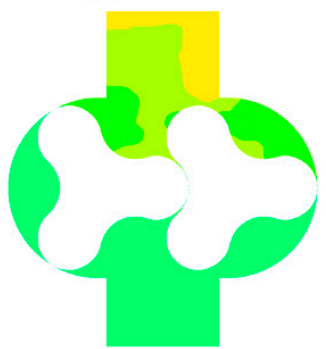

(f) $0.310 \mathrm{~s}$

Figure 18. Static pressure contours of the Roots pump when the rotational speed is $1000 \mathrm{rpm}$. Flow time: (a) $0.300 \mathrm{~s}$; (b) $0.302 \mathrm{~s}$; (c) $0.304 \mathrm{~s}$; (d) $0.306 \mathrm{~s}$; (e) $0.308 \mathrm{~s}$; (f) $0.310 \mathrm{~s}$. 


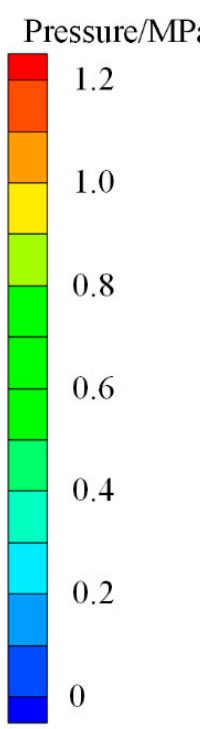

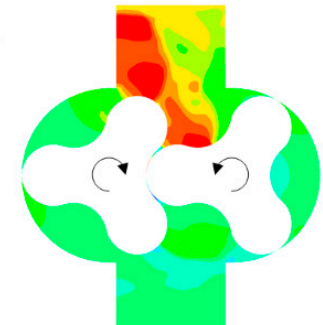

(a) $0.0750 \mathrm{~s}$

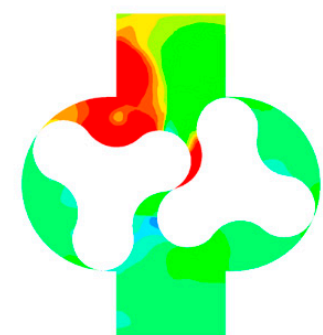

(d) $0.0765 \mathrm{~s}$

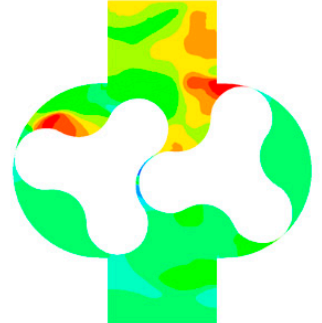

(b) $0.0755 \mathrm{~s}$

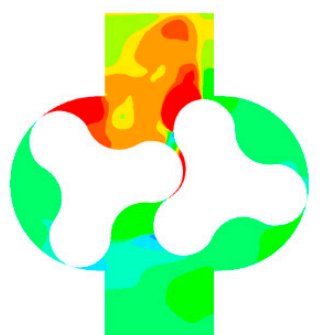

(e) $0.0770 \mathrm{~s}$

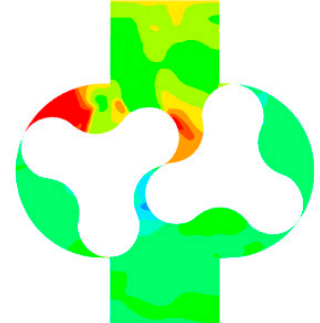

(c) $0.0760 \mathrm{~s}$

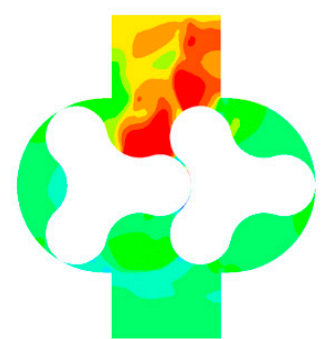

(f) $0.0775 \mathrm{~s}$

Figure 19. Static pressure contours of the Roots pump when the rotational speed is $4000 \mathrm{rpm}$. Flow time: (a) $0.0750 \mathrm{~s}$; (b) $0.0755 \mathrm{~s}$; (c) $0.0760 \mathrm{~s}$; (d) $0.0765 \mathrm{~s}$; (e) $0.0770 \mathrm{~s}$; (f) $0.0775 \mathrm{~s}$.

The value of the pump efficiency, which can be expressed by the multiplication of the volumetric efficiency and the flow efficiency, becomes smaller with the increase in the rotational speed.

\subsection{Effect of Pressure Ratio}

It can be seen that the liquid phase in the fluid is helpful in sealing the Roots pump, and reduces the temperature increase during the compression process [7]. This indicates that the gas-liquid mixture Roots pump has the potential to achieve a high pressure ratio. To study the flow characteristics of the Roots pump under various pressure ratios, numerical simulations were also conducted for pressure ratios from 4 to 10 . The inlet pressure was set as $0.46 \mathrm{MPa}$, the inlet $\mathrm{CO}_{2}$ volume fraction was 0.8 , and the rotational speed was $2500 \mathrm{rpm}$. The relevant parameters are shown in Table 6.

Table 6. Setting parameters of simulations with various pressure ratios.

\begin{tabular}{ccccc}
\hline Case Numbers & Inlet Pressure & $\begin{array}{c}\text { Inlet } \mathrm{CO}_{2} \text { Volume } \\
\text { Fraction }\end{array}$ & Rotational Speed & Pressure Ratio \\
\hline 1 & & & & 4 \\
2 & & & & 6 \\
3 & $0.46 \mathrm{MPa}$ & 0.8 & & 8 \\
4 & & & & 10 \\
\hline
\end{tabular}

The efficiencies at different pressure ratios were obtained, and are illustrated in Figure 20.

The flow efficiency gradually declines from $52 \%$ to $42 \%$ with the increase in the pressure ratio, while the volumetric efficiency decreases from $92 \%$ to $76 \%$. The pump efficiency presents a downward trend from $48 \%$ to $33 \%$ when the pressure ratio increases from 2 to 10. The pressure contours of the Roots pump at the pressure ratios of 6 and 10 are shown in Figures 21 and 22, respectively.

The pressure field in the Roots pump is similar at different pressure ratio conditions, except for the differences in the pressure pulsation frequency and the pressure values. 


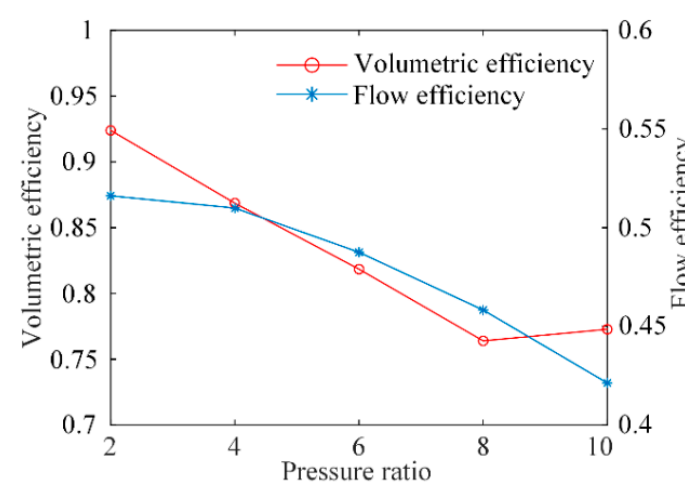

(a)

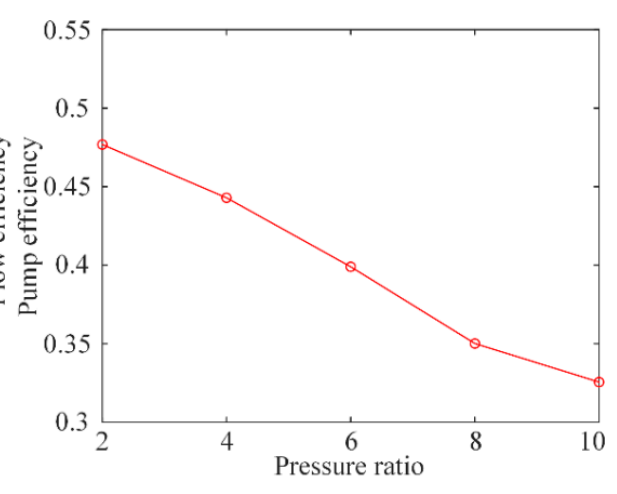

(b)

Figure 20. Efficiencies of the Roots pump under various pressure ratios. (a) volumetric efficiency and flow efficiency; (b) pump efficiency.

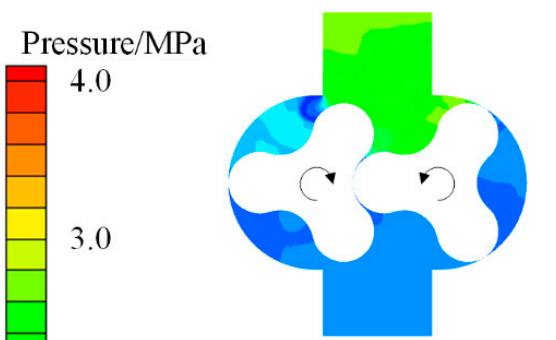

(a) $0.1200 \mathrm{~s}$

2.0

1.0

0

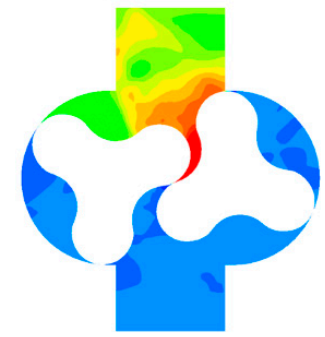

(d) $0.1224 \mathrm{~s}$

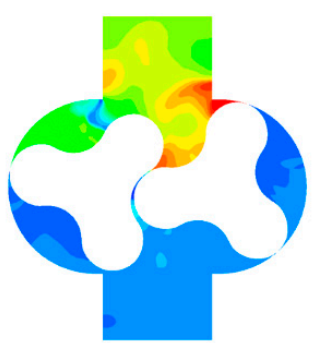

(b) $0.1208 \mathrm{~s}$

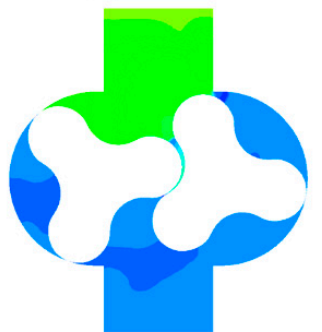

(e) $0.1232 \mathrm{~s}$

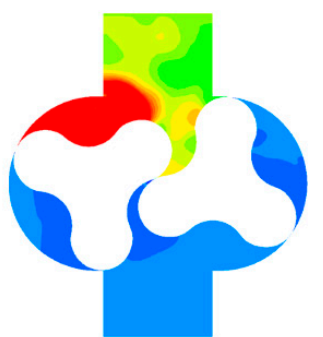

(c) $0.1216 \mathrm{~s}$

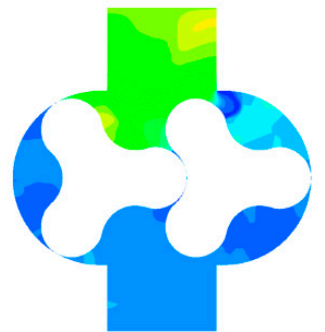

(f) $0.1240 \mathrm{~s}$

Figure 21. Pressure contours of the Roots pump when the pressure ratio is 6. Flow time: (a) $0.1200 \mathrm{~s}$; (b) $0.1208 \mathrm{~s}$; (c) $0.1216 \mathrm{~s}$; (d) $0.1224 \mathrm{~s}$; (e) $0.1232 \mathrm{~s}$; (f) $0.1240 \mathrm{~s}$.

For the volumetric efficiency, the pressure difference between the outlet and inlet zones increases gradually with the increased pressure ratio, leading to an increase in the leakage in the gaps. However, as the pressure difference continues to increase, the increment of the leakage is insensitive to the pressure difference. In addition, when the pressure in the outlet zone is high, the gas volume fraction becomes lower, which contributes to the sealing of the gaps. Therefore, the leakage does not increase and the volume efficiency tends to remain constant when the pressure ratio reaches a certain degree.

For the flow efficiency, the compression of the fluid in the pump depends on the joint action of the rotors' rotation and the backflow of the high-pressure fluid outside the pump. When the pressure ratio is low, the gas volume fraction of the backflow is high, which has the characteristics of small inertia and high compressibility. Therefore, the maximum pressure in the outlet zone is relatively low, and the flow efficiency is high. When the pressure ratio increases, the pressure of the backflow is high and the gas volume fraction is low, leading to an intense mixing process with the fluid in the outlet zone. Therefore, the maximum pressure in the outlet zone is much higher than that of the outlet boundary, and the flow efficiency is low. 


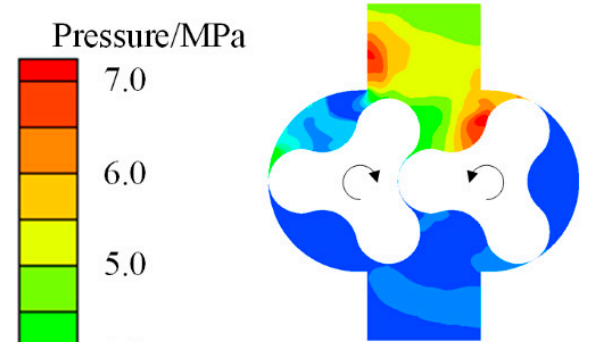

(a) $0.1200 \mathrm{~s}$

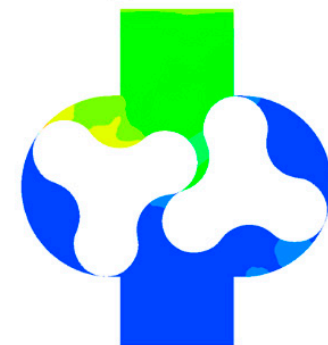

(d) $0.1224 \mathrm{~s}$

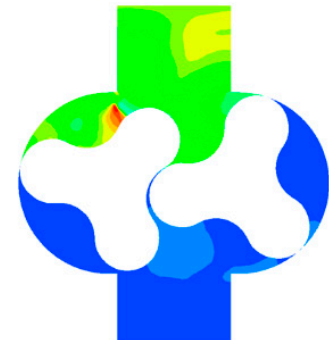

(b) $0.1208 \mathrm{~s}$

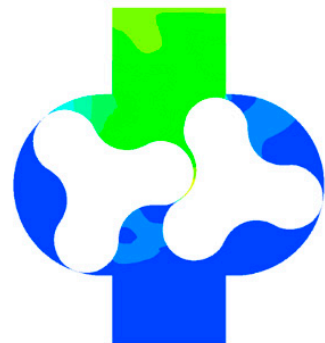

(e) $0.1232 \mathrm{~s}$

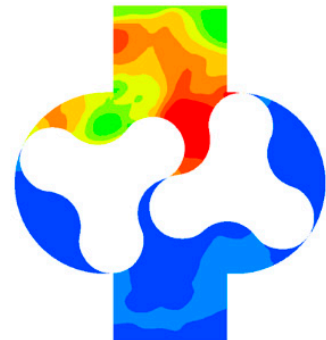

(c) $0.1216 \mathrm{~s}$

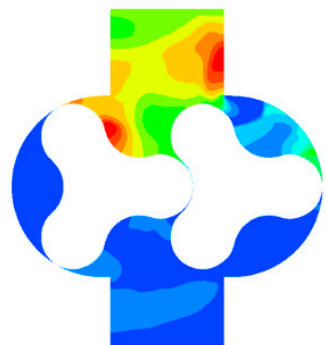

(f) $0.1240 \mathrm{~s}$

Figure 22. Pressure contours of the Roots pump when the pressure ratio is 10. Flow time: (a) $0.1200 \mathrm{~s}$; (b) $0.1208 \mathrm{~s}$; (c) $0.1216 \mathrm{~s}$; (d) $0.1224 \mathrm{~s}$; (e) $0.1232 \mathrm{~s}$; (f) $0.1240 \mathrm{~s}$.

As the volumetric efficiency and the flow efficiency decrease with the increase in the pressure ratio, the value of the pump efficiency becomes smaller as well.

Through the analysis of the characteristics of gas-liquid mixture Roots pumps under various working conditions, the density, compressibility, and specific heat capacity of the mixture fluid were found to be the main factors leading to the performance variations of Roots pumps. These fluid properties are jointly governed by the gas and liquid phases. Therefore, the change in the gas volume fraction of the fluid affects the flow characteristics in Roots pumps, leading to the variation in the backflow rate and the outlet zone pressure and temperature. As a result, the flow efficiency changes with the working conditions. In addition, the sealing of Roots pumps, which determines their volumetric efficiency, is also affected by the fluid properties and the outlet zone pressure.

\section{Conclusions}

The performance of the Roots pump operating with gas-liquid mixture under various inlet $\mathrm{CO}_{2}$ volume fractions, rotational speeds, and pressure ratios was studied in this paper. The main findings are:

(1) When the inlet $\mathrm{CO}_{2}$ volume fraction increases from 0.8 to 1 , the volumetric efficiency first increases from $92 \%$ to $97 \%$, then decreases sharply to $80 \%$. The flow efficiency increases from $52 \%$ to $73 \%$, while the pump efficiency also increases from $48 \%$ to $64 \%$, and then decreases to $59 \%$. This is due to the differences in the properties of the gas and liquid phases. The decrease in the liquid phase volume flow leads to the deterioration of the sealing of the gaps and reduces the backflow's impact in the outlet zone;

(2) When the rotational speed increases from $1000 \mathrm{rpm}$ to $4000 \mathrm{rpm}$, the volumetric efficiency increases from $90 \%$ to $95 \%$, the flow efficiency decreases from $75 \%$ to $46 \%$, and the pump efficiency decreases from $67 \%$ to $43 \%$. The pressure difference between the inlet and outlet is considered to be the main factor governing the leakage in the Roots pump. The volumetric efficiency increases with the increase in the rotational speed, since the leakage remains unchanged while the theoretical volume flow rate increases. At high rotational speeds, the extrusion effect of the rotors on the fluid in the pump is more significant, leading to a decrease in flow efficiency;

(3) As the pressure ratio increases from 2 to 10, the volumetric efficiency drops from $92 \%$ to $77 \%$ and then remains stable, while the flow efficiency drops from $52 \%$ to $42 \%$, 
resulting in a decrease in the pump efficiency from $48 \%$ to $33 \%$. The increase in the pressure ratio enhances the leakage, but it also reduces the gas volume fraction in the outlet zone, which is helpful in reducing the leakage. The combined effects make the volume efficiency first decrease, and then stabilize. Both of the effects can aggravate the impact of the fluid in the outlet zone and reduce the flow efficiency.

In gas-liquid mixture Roots pumps, the liquid phase is helpful to enhance the sealing and reduce the temperature rise due to the compression, which effectively improves the operating pressure ratio of the Roots pump. At the same time, the structure of Roots pumps can adapt to the change in the $\mathrm{CO}_{2}$ volume fraction of the working fluid in a wide range. However, this study shows that the backflow in the outlet zone of the pump is quite serious under the conditions of high pressure, small $\mathrm{CO}_{2}$ volume fraction, and high rotational speed, which may lead to a large periodic impact load on the rotors. This may have a negative impact on the operation and structural stability of Roots pumps. Though the present study does not cover this aspect, the dynamic characteristics of gas-liquid mixture Roots pumps are worthy of further analysis in future.

Author Contributions: Conceptualization, Q.G.; funding acquisition, K.Q.; investigation, K.L. and Q.G.; methodology, Q.G. and K.Q.; resources, K.L.; writing—original draft, Q.G.; writing-review and editing, D.L. and C.H. All authors have read and agreed to the published version of the manuscript.

Funding: This research is supported by the National Natural Science Foundation of China (NSFC) (Grant No. 51805435).

Institutional Review Board Statement: Not applicable.

Informed Consent Statement: Not applicable.

Data Availability Statement: Not applicable.

Acknowledgments: The authors would like to thank the National Natural Science Foundation of China (NSFC) for the sponsorship.

Conflicts of Interest: The authors declare no conflict of interest.

\section{Nomenclature}

a Half-center distance of rotors

$b \quad$ Distance of rotor and addendum arc center

D Rotor diameter

$D_{0} \quad$ Inlet and outlet diameter

$E_{k} \quad$ Internal energy of phase $\mathrm{k}$

$\vec{F} \quad$ Body force

$g \quad$ Gravitational acceleration

$h_{k} \quad$ Sensible enthalpy of phase $\mathrm{k}$

$i \quad$ Number of standard uncertainty component

$k \quad$ Isentropic index; phase $\mathrm{k}$

$k_{\alpha} \quad$ Confidence factor

$k_{\text {eff }} \quad$ Effective thermal conductivity

$L \quad$ Rotor length

$m_{g c} \quad$ Liquid theoretical mass flow rate

$m_{\&} \quad$ Mass exchange

$M_{1} \quad$ Moment of left rotor

$M_{2} \quad$ Moment of right rotor

$N \quad$ Number of standard uncertainty component

$n \quad$ Number of phases; number of measurements; rotational speed

$p \quad$ Computational domain pressure

$P_{S} \quad$ Inlet pressure

$P_{d} \quad$ Outlet pressure

$Q_{t h} \quad$ Theoretical volume flow rate

$Q_{l c} \quad$ Liquid phase theoretical volume flow rate 


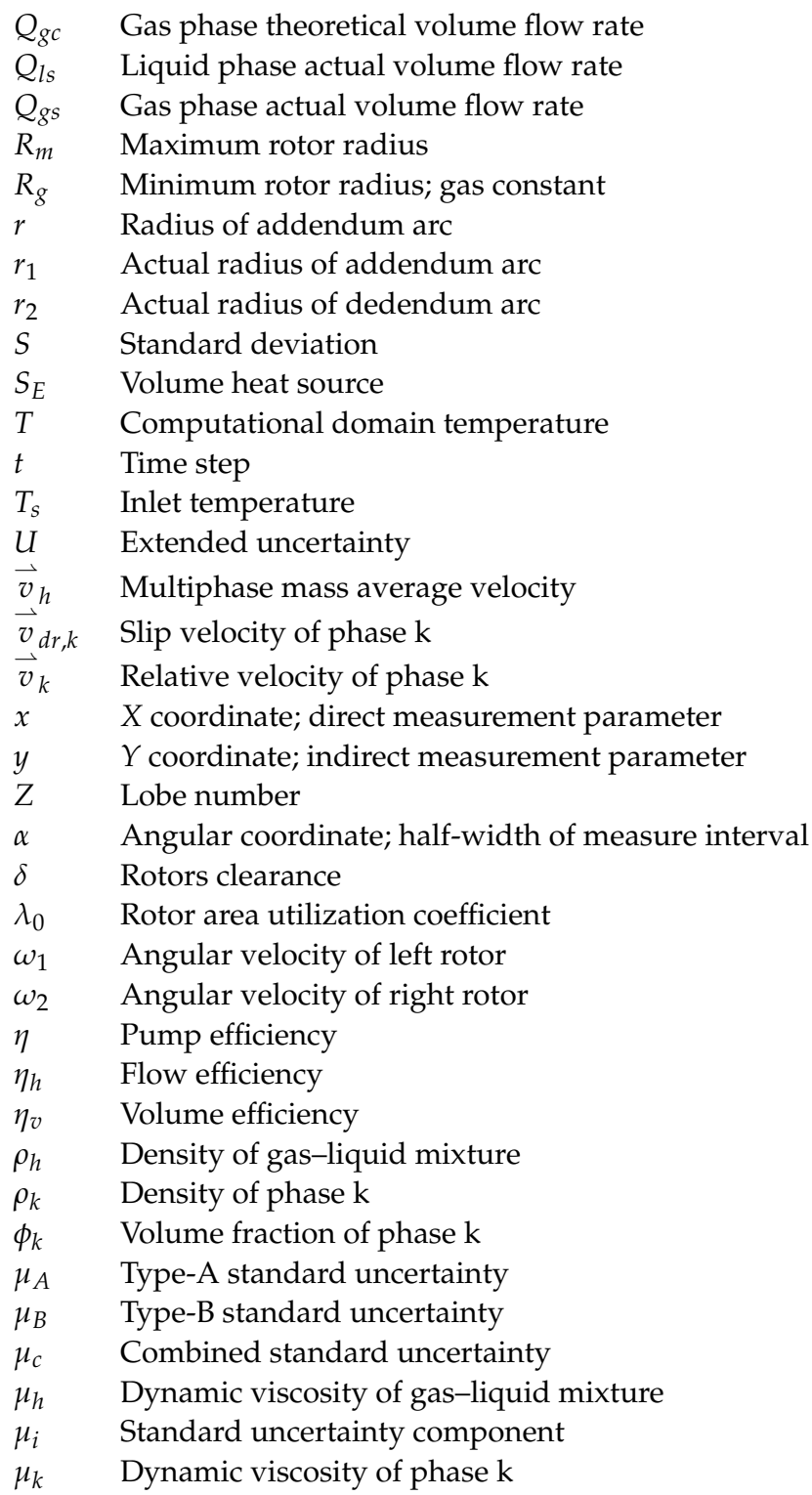

\section{References}

1. Kiely, D. Review of underwater thermal propulsion. In Proceedings of the 30th Joint Propulsion Conference and Exhibit, Indianapolis, IN, USA, 27-29 June 1994; Institute of Aeronautics and Astronautics: Reston, VA, USA, 1994; pp. 1-5.

2. Si, Q.; Bois, G.; Liao, M.; Zhang, H.; Cui, Q.; Yuan, S. A Comparative Study on Centrifugal Pump Designs and Two-Phase Flow Characteristic under Inlet Gas Entrainment Conditions. Energies 2019, 13, 65. [CrossRef]

3. Cao, F.; Gao, T.; Li, S.; Xing, Z.; Shu, P. Experimental analysis of pressure distribution in a twin screw compressor for multiphase duties. Exp. Therm. Fluid Sci. 2011, 35, 219-225. [CrossRef]

4. He, Z.; Wang, T.; Wang, X.; Peng, X.; Xing, Z. Experimental Investigation into the Effect of Oil Injection on the Performance of a Variable Speed Twin-Screw Compressor. Energies 2018, 11, 1342. [CrossRef]

5. Lobsinger, T.; Hieronymus, T.; Brenner, G. A CFD Investigation of a 2D Balanced Vane Pump Focusing on Leakage Flows and Multiphase Flow Characteristics. Energies 2020, 13, 3314. [CrossRef]

6. Zhang, W.; Yu, Z.; Zahid, M.N.; Li, Y. Study of the Gas Distribution in a Multiphase Rotodynamic Pump Based on Interphase Force Analysis. Energies 2018, 11, 1069. [CrossRef]

7. Guo, Q.; Qin, K.; Li, D.; Huang, C.; Luo, K. Numerical investigation and performance enhancement of roots pumps operating with gas-liquid mixtures. Vacuum 2020, 176, 109303. [CrossRef]

8. Cai, Y.; Yao, L.; Wei, G. Generation of tooth profile for Roots rotor based on virtual linkage associated with Assur group. Adv. Mech. Eng. 2016, 8, 1-8. [CrossRef]

9. Bhuyan, P.; Ghosh, S. Performance prediction of Roots blower based on shape of the rotor-profile using FVM with adaptive mesh redistribution technique and GA-tuned neural network. J. Braz. Soc. Mech. Sci. Eng. 2019, 41, 433. [CrossRef] 
10. Wang, J.; Liu, R.; Yang, S.; Li, H.; Wang, Z.; Li, Q. Geometric study and simulation of an elliptical rotor profile for Roots vacuum pumps. Vacuum 2018, 153, 168-175. [CrossRef]

11. Laczik, B.; Zentay, P.; Horvath, R. A new approach for designing gear profiles using closed complex equations. Acta Polytech. Hung. 2014, 11, 159-172.

12. Hsieh, C.-F. A new curve for application to the rotor profile of rotary lobe pumps. Mech. Mach. Theory 2015, 87, 70-81. [CrossRef]

13. Maqsood, M.; Usman, A.; Bodla, M.F.; Ali, J. Evaluation of performance parameters of indigenously developed roots pumping system. IOP Conf. Ser. Mater. Sci. Eng. 2016, 146, 012047. [CrossRef]

14. Jou, R.-Y.; Huang, W.-H. A Measurement System for the Performance Evaluation of Roots Blowers. In Proceedings of the 2018 IEEE International Conference on Advanced Manufacturing (ICAM), Yunlin, Taiwan, 16-18 November 2018; Institute of Electrical and Electronics Engineers (IEEE): Piscataway, NJ, USA, 2018; pp. 380-383.

15. Singh, G.; Sun, S.; Kovacevic, A.; Li, Q.; Bruecker, C. Transient flow analysis in a Roots blower: Experimental and numerical investigations. Mech. Syst. Signal Process. 2019, 134, 106305. [CrossRef]

16. Huang, S.; Guo, J.; Yang, F.X. Numerical simulation of 3D unsteady flow in a rotating pump by dynamic mesh technique. IOP Conf. Ser. Mater. Sci. Eng. 2013, 52, 022030. [CrossRef]

17. Sun, S.; Zhao, B.; Jia, X. Three-dimensional numerical simulation and experimental validation of flows in working cham-bers and inlet/outlet pockets of Roots pump. Vacuum 2017, 137, 195-204. [CrossRef]

18. Peng, X.; He, Z.; Shu, P. Design improvement on involute profile of Roots blower rotors. Compress. Blower Fan Technol. 2000, 3, 3-5. (In Chinese)

19. Zhang, Q.; Wang, S.; Shi, J.; Wang, X.; Tomovic, M. Performance degradation model of roots pump in vacuum system based on leakage of rotor wear. In Proceedings of the 2016 IEEE 11th Conference on Industrial Electronics and Applications (ICIEA), Hefei, China, 5-7 June 2016; pp. 2174-2179. [CrossRef]

20. Gordeeva, U.S.; Demikhov, K.E.; Ochkov, A.A. Specifics of the application of mechanical vacuum pumps in vacuum distillation units used in chemical and oil and gas industries. Nanosci. Nanotech. Nano-SciTech 2019, 2141, 030011. [CrossRef]

21. Casari, N.; Fadiga, E.; Pinelli, M.; Suman, A.; Kovacevic, A.; Rane, S.; Ziviani, D. Numerical investigation of oil injection in a Roots blower operated as expander. IOP Conf. Ser. Mater. Sci. Eng. 2019, 604, 012075. [CrossRef]

22. Hsieh, C.-F.; Deng, Y.-C. A design method for improving the flow characteristics of a multistage Roots pumps. Vacuum 2015, 121, 217-222. [CrossRef]

23. Hsieh, C.-F.; Zhou, Q.-J. Fluid analysis of cylindrical and screw type Roots vacuum pumps. Vacuum 2015, 121, 274-282. [CrossRef]

24. Liu, X.; Lu, J.; Gao, R. Numerical investigation of the aerodynamic performance affected by spiral inlet and outlet in a posi-tive displacement blower. Chin. J. Mech. Eng. 2013, 26, 957-966. [CrossRef]

25. Sun, S.-K.; Jia, X.-H.; Xing, L.-F.; Peng, X.-Y. Numerical study and experimental validation of a Roots blower with backflow design. Eng. Appl. Comput. Fluid Mech. 2018, 12, 282-292. [CrossRef]

26. Li, Y.-B.; Guo, D.-S.; Li, X.-B. Mitigation of radial exciting force of rotary lobe pump by gradually varied gap. Eng. Appl. Comput. Fluid Mech. 2018, 12, 711-723. [CrossRef]

27. Cai, Y.; Yao, L. Roots Blower with Gradually Expanding Outlet Gap: Mathematical Modelling and Performance Simulation. In Proceedings of the 2nd International Conference on Advances in Mechanical Engineering and Industrial Informatics (AMEII 2016), Hangzhou, China, 9-10 April 2016; pp. 653-660. [CrossRef]

28. Ohtani, I.; Iwamoto, T. Reduction of Noise in Roots Blower. Bull. JSME 1981, 24, 547-554. [CrossRef]

29. Vizgalov, S.V.; Volkov, M.V.; Chekushkin, G.N.; Khisameev, I.G. Enhancing the efficiency of a three-lobe roots blower by means of by-passing gas to the working cavity through an ejector adaptor. In Proceedings of the Oil and Gas Engineering (OGE-2017), Omsk, Russia, 24 April 2017; pp. 1-7. [CrossRef]

30. Vizgalov, S.V.; Chekushkin, G.N.; Volkov, M.V. Investigation of three lobes roots blower with special ejector. IOP Conf. Ser. Mater. Sci. Eng. 2015, 90, 012082. [CrossRef]

31. Xing, L.; Feng, J.; Chen, W.; Xing, Z.; Peng, X. Development and Testing of a Roots Pump for Hydrogen Recirculation in Fuel Cell System. Appl. Sci. 2020, 10, 8091. [CrossRef]

32. Feng, J.; Xing, L.; Wang, B.; Wei, H.; Xing, Z. Effects of Working Fluids on the Performance of a Roots Pump for Hydrogen Recirculation in a PEM Fuel Cell System. Appl. Sci. 2020, 10, 8069. [CrossRef]

33. De Graff, B.; Howell, M.; Kim, S. SNS cryogenic test facility Kinney vacuum pump commissioning and operation at $2 \mathrm{~K}$. In Proceedings of the Joint Cryogenic Engineering Conference/International Cryogenic Materials Conference, Madison, WI, USA, 9-13 July 2017; Iop Publishing Ltd.: Bristol, UK; Volume 278, p. 012161.

34. He, Y.; Sun, D.; Liu, J.; Zhu, B. Optimization of a turbocharger and supercharger compound boosting system for a Miller cycle engine. Proc. Inst. Mech. Eng. Part D J. Automob. Eng. 2017, 232, 238-253. [CrossRef]

35. Su, C. Roots Blower and Application; Changsha Central South University of Technology Press: Changsha, China, 1999; pp. 29-37. (In Chinese)

36. Ansys. Ansys Help, Ansys Fluent; Version 18.0; ANSYS Inc.: Canonsburg, PA, USA, 2016.

37. Menter, F.R. Two-equation eddy-viscosity turbulence models for engineering applications. AIAA J. 1994, 32. [CrossRef] 